Article publié par le Laboratoire de Construction en Béton de l'EPFL

\begin{tabular}{|l|l|}
\hline Title: & $\begin{array}{l}\text { Strength of reinforced concrete footings without transverse reinforcement } \\
\text { according to limit analysis }\end{array}$ \\
\hline Authors: & Simões J. T., Faria D. M. V., Fernández Ruiz M., Muttoni A. \\
\hline Published in: & Engineering structures \\
\hline DOI & $10.1016 /$ j.engstruct.2016.01.010 \\
\hline $\begin{array}{l}\text { Volume: } \\
\text { Pages: }\end{array}$ & $\begin{array}{l}\text { Vol. 112 } \\
\text { pp. 146-161 }\end{array}$ \\
\hline Country: & UK \\
\hline Year of publication: & 2016 \\
\hline Type of publication: & Peer reviewed journal article \\
\hline
\end{tabular}

Please quote as:

Simões J. T., Faria D. M. V., Fernández Ruiz M., Muttoni A., Strength of reinforced concrete footings without transverse reinforcement according to limit analysis, Engineering structures, Vol. 112, UK, 2016, pp. 146-161. 


\title{
Strength of reinforced concrete footings without transverse reinforcement according to limit analysis
}

\author{
João T. Simões*, Duarte M.V. Faria, Miguel Fernández Ruiz, Aurelio Muttoni \\ École Polytechnique Fédérale de Lausanne, ENAC, Station 18, CH-1015 Lausanne, Switzerland
}

\section{A R T I C L E I N F O}

\section{Article history:}

Received 19 January 2015

Revised 6 January 2016

Accepted 7 January 2016

\section{Keywords:}

Limit analysis

Kinematical theorem

Footings

Flexural strength

Punching shear strength

Flexural-shear regime

Simplified formulations

\begin{abstract}
A B S T R A C T
Isolated footings are reinforced concrete elements whose flexural and punching shear strengths are usually governing for their design. In this work, both failure modes and their interaction are investigated by means of the kinematical theorem of limit analysis. Previous works in this domain have traditionally considered failure mechanisms based on a vertical penetration of a punching cone. In this work, two enhanced failure mechanisms are investigated considering not only a vertical penetration of the punching cone, but also a rotation of the outer part of the footing, allowing to consider the role of both bottom and top reinforcements on the failure load. A rigid-plastic behavior with a Mohr-Coulomb yield criterion is considered for the concrete and a uniaxial rigid-plastic behavior is assumed for the reinforcement bars. The analysis shows that a smooth transition between flexural and punching shear failure occurs, corresponding to a flexural-shear regime. With respect to the punching shear failure regime, it is shown that the top reinforcement might play an important role (a fact usually neglected by previous investigations). Simplified formulations, allowing easy calculation of the load carrying capacity of footings, are derived and compared to the solutions according to limit analysis. Both theoretical and approximated solutions are finally compared with experimental results, showing consistent agreement.
\end{abstract}

(c) 2016 Elsevier Ltd. All rights reserved.

\section{Introduction}

Concrete footings are commonly used as foundations for buildings and bridges. Although the load carrying capacity of footings subjected to a concentrated loading originated from a column has been the object of different research works [e.g. 1-18], there is still not yet a consensus on a consistent method with physical basis for its design. In this paper, a rational approach is presented on the basis of the kinematical theorem of limit analysis, providing an upper bound solution for the load carrying capacity of these members. The approach may be applied to footings subjected to a distributed soil reaction (as the case of footings with a uniform soil reaction, see Fig. 1(a)) or to footings with concentrated reactions (as the case of pile caps, see Fig. 1(b)).

One of the first applications of limit analysis to reinforced concrete members subjected to in-plane shear was proposed by Drucker [19], who developed both a lower and an upper bound solution for a beam without shear reinforcement (refer to Fig. 2 (a) and (b)). Drucker [19] also showed that the proposed upper

\footnotetext{
* Corresponding author.

E-mail addresses: joao.simoes@epfl.ch (J.T. Simões), duarte.viulafaria@epfl.ch (D.M.V. Faria), miguel.fernandezruiz@epfl.ch (M. Fernández Ruiz), aurelio.muttoni@ epfl.ch (A. Muttoni).
}

and lower bound solutions provided the same failure load and thus corresponded to the exact solution according to limit analysis. According to Drucker [19], failure in shear occurs by crushing of the inclined compression strut (with or without yielding of longitudinal reinforcement). This has been observed to be consistent with experimental evidences only for beams with low slenderness (see Fig. 2(c), for beam B1 of Leonhardt and Walther [20]). For larger slenderness (Fig. 2(d), beam B6 of Leonhardt and Walther [20]), failure occurs instead by an unstable propagation of a critical shear crack developing through the compression strut. In these latter cases, the strength is no longer controlled by the concrete crushing and strain localization occurs. Thus, size effect and other phenomena govern [21,22] and the application of limit analysis is in principle unsuitable for these cases. Analogously to the behavior observed in beams, the strength of slender two-way slabs without shear reinforcement might be governed by the development of a critical shear crack, thus being in the range where limit analysis is not applicable [23]. On the contrary, footings and compact slabs failing in punching can be considered to be similar to beams with low shear slenderness failing by crushing of concrete struts, thus corresponding to the range of cases where limit analysis may be applied.

Limit analysis has already been applied in several cases focusing on the flexural and shear capacity of plain and reinforced concrete 


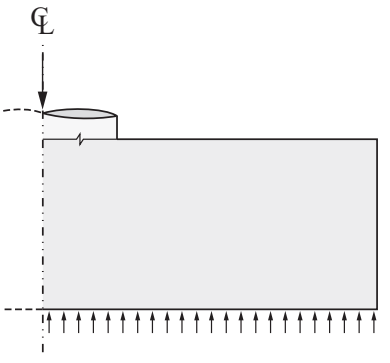

(a)

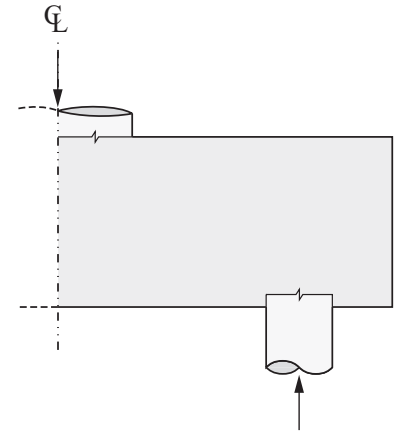

(b)
Fig. 1. Schematically representation of (a) footing with uniform reaction and (b) pile caps with concentrated reactions.

elements as joints, beams and slabs [e.g. 19,24-46]. With respect to punching shear in slabs, Braestrup et al. [28], Nielsen et al. [31] and Braestrup [32], presented a first theoretical solution based on the kinematical theorem, considering the concrete as a rigid-plastic material with a modified Coulomb yield criterion. The adopted failure mechanism consisted on a vertical shift of the outer slab portion, see Fig. 3. Later, Jiang and Shen [37], Bortolotti [39], Kuang [40] and Salim and Sebastian [42] also applied the upper bound theorem, adopting the same mechanism proposed by Braestrup et al. [28], but with some modifications, namely, in the adopted failure criterion for the concrete.

A drawback of the above mentioned works, based on limit analysis to punching shear in slabs, is that the adopted failure mechanism only considers a vertical displacement along the failure surface, therefore neglecting the possibility of rotations leading to the activation of both bottom flexural and top reinforcement (and thus allowing only the analysis of punching regimes and not flexural or combined flexural-shear regimes). Moreover, all the above mentioned works deal mostly with punching shear strength of general slabs, where the application of this theory becomes potentially questionable (influence of size effect and other phenomena [22]).

In the present work, a theoretical solution for the load carrying capacity of axisymmetric isolated footings with low slenderness is presented. Two different failure mechanisms were selected as potentially governing. Both failure mechanisms consider that two footing portions are separated by a failure surface, which is assumed to be rotationally symmetric. The inner portion is considered to be rigid, while the outer portion deforms due to tangential moments according to a conical shape. Contrary to previous works, the mechanisms considered in the present paper lead to the consideration not only of the internal energy dissipated along the

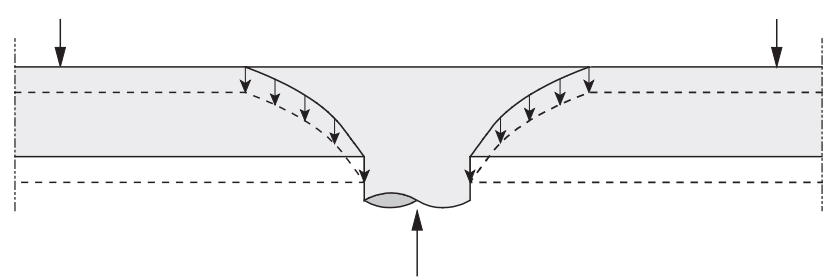

Fig. 3. Kinematically admissible failure mechanism proposed by Braestrup et al. [28] and Braestrup [32].

failure surface, but also of the internal energy dissipated in the bottom and top reinforcement, as well as in the concrete compression zone due to tangential bending. The governing failure mechanism is obtained in each case by minimization of the failure load accounting for the fact that both failure mechanisms provide an upper bound solution of the actual failure load.

On that basis, simplified solutions are also proposed, consistent with the upper bound solutions developed. Finally, both approximated and optimized solutions are compared with available experimental tests results, showing the consistency and accuracy of the approach.

\section{Kinematical theorem of limit analysis applied to isolated reinforced concrete footings}

In limit analysis, materials are assumed to behave in a perfectly plastic manner [45]. The application of the limit analysis is based on limit state theorems, and, in this paper, the kinematical theorem is used, providing an upper bound of the load carrying capacity. Global equilibrium is investigated stating that the rate of internal energy dissipated has to be balanced by the rate of external work for a licit (kinematically admissible) mechanism.

In this work, a rigid-plastic compressive behavior of concrete with a Mohr-Coulomb yield criterion is assumed, see Fig. 4 (a) and (b). Also the normality condition (strain rate vector normal to the yield locus) is respected. Due to the brittle behavior of concrete in tension, tensile strength is neglected (introduced as a tension cut-off in the plasticity surface). In order to take into account the brittleness of concrete in compression as well as the influence of transverse strains on concrete strength, a plastic compressive strength $f_{c p}$ is considered, which is given by [44]:

$f_{c p}=f_{c} \cdot \eta_{\varepsilon} \cdot \eta_{f c}$

where $f_{c}$ refers to the cylinder concrete compressive strength, $\eta_{\varepsilon}$ and $\eta_{f c}$ represent the reduction factors accounting, respectively, for the presence of transverse strains and for the brittleness of high-strength concrete. Although different approaches have already

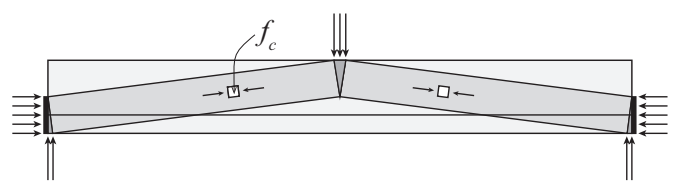

(a)

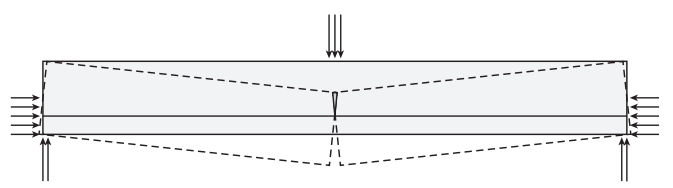

(b)

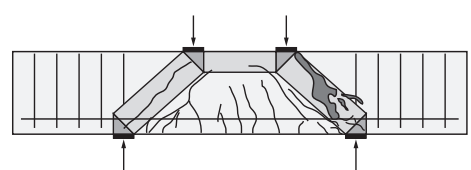

(c)

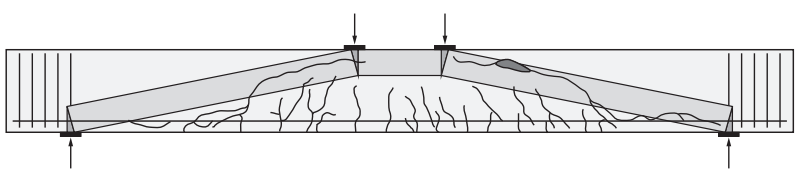

(d)

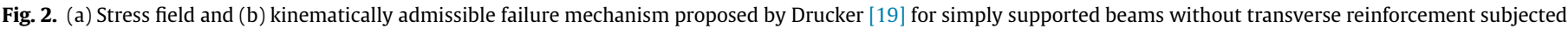
to a single load: cracking pattern and location of theoretical strut of (c) beam B1 and (d) beam B6 by Leonhardt and Walther [20]. 
been proposed to calculate the value of the reduction factor accounting for the presence of transverse strains $\eta_{\varepsilon}$ [e.g. $38,41,47,48]$ and of a global reduction factor $\eta=\eta_{\varepsilon} \cdot \eta_{f c}$ [e.g. 45], further investigations remain to be done in this field, specifically in what regards the characterization of the state of strains of footings when subjected to concentrated loads. Thus, constant values of $\eta_{\varepsilon}$ will be assumed in this work (and are considered constant for all internal dissipation contributions, refer to Section 5). Regarding the reduction factor accounting for the brittleness of the highstrength concrete, it may be obtained as $[38,41,44,49]$ :

$\eta_{f c}=\left(\frac{f_{c 0}}{f_{c}}\right)^{1 / 3} \leqslant 1$

with $f_{c 0}=30 \mathrm{MPa}$ [44]. The consideration of the Mohr-Coulomb yield criterion with a tension cut-off leads to the definition of three potential regimes occurring along the failure surface (refer to Fig. 4 (b)), whose strain rates as well as principal stresses may be defined as follows:

Regime A : $\left\{\begin{array}{l}\frac{\dot{\varepsilon}_{3}}{\dot{\varepsilon}_{1}}=-\frac{1-\sin (\varphi)}{1+\sin (\varphi)} \\ \sigma_{3}=-f_{c p}+\frac{1+\sin (\varphi)}{1-\sin (\varphi)} \cdot \sigma_{1}\end{array}\right.$

Regime B : $\left\{\begin{array}{l}-\frac{1-\sin (\varphi)}{1+\sin (\varphi)}<\frac{\dot{\varepsilon}_{3}}{\dot{\varepsilon}_{1}}<0 \\ \sigma_{1}=0 \\ \sigma_{3}=-f_{c p}\end{array}\right.$

Regime $C:\left\{\begin{array}{l}\dot{\varepsilon}_{3}=0 \\ \dot{\varepsilon}_{1}=0 \\ \sigma_{1}=0 \\ -f_{c p}<\sigma_{3}<0\end{array}\right.$

where $\dot{\varepsilon}_{1}, \dot{\varepsilon}_{3}$ and $\sigma_{1}, \sigma_{3}$ are respectively the principal strain rates and the principal stresses; $\varphi$ is the concrete friction angle, herein considered equal to $\varphi=37^{\circ}$ (i.e. $\tan (\varphi)=0.75$ [45]). A uniaxial rigid-plastic behavior in both compression and tension of reinforcement steel bars is also assumed, refer to Fig. 4(c) (i.e., dowel action is neglected). It has to be noted that positive strain rates and stresses refer to tension.

The geometrical and material properties used to describe the problem are presented in Fig. 5(a) (see Appendix D for Notation). For a given footing geometry, two failure mechanisms (shown in Fig. 5(b) and (c)) are considered. The minimum load carrying capacity that results from the analysis using both mechanisms is the considered upper bound failure load. Both mechanisms consider that two portions of the footing are separated by an axisymmetric narrow plastic zone (see Fig. 5(a)), where the velocity field results from the relative rotation rate $\dot{\psi}$ (Fig. 5) around an instantaneous center of rotation.
The kinematics considered for both mechanisms differ in the admissible location for the instantaneous center of rotation, as well as in the rotation direction. As shown in Fig. 5(b), in the first mechanism (M1), the location of the instantaneous center of rotation in the radial axis is considered to be behind the edge of the column $\left.\left.\left(r_{I C R} \in\right]-\infty ; r_{c}\right]\right)$, while in the vertical direction it is admitted to be above the bottom reinforcement $\left(z_{I C R} \in\right] 0 ; \infty[)$. The kinematically admissible mechanism M1 presents a counterclockwise rotation when the instantaneous center of rotation is not in the infinite. This mechanism is often assumed to be the one occurring in flexural as well as punching shear failures of flat slabs. For flexural failures, the instantaneous center of rotation is close to the tip of the failure surface at the column edge, leading to a failure with an important rotation component. For the punching shear failure, the location of the instantaneous center of rotation in radial direction shifts toward infinite $\left(r_{I C R} \rightarrow-\infty\right)$. In the latter case, the mechanism consists in a vertical shift of the outer portion of the footing, without activation of both bottom and top reinforcements (as dowelling of the reinforcement is neglected). This case corresponds to the failure mechanism originally proposed by Braestrup et al. [28], where only the internal energy dissipated along the failure surface contributes to the load carrying capacity.

As shown in Fig. 5(c), the location of the instantaneous center of rotation in the kinematics admitted for the second mechanism (M2) is assumed to be below or at the level of the bottom reinforcement $\left.\left.\left(z_{I C R} \in\right]-\infty ; 0\right]\right)$ and outside the radius where the reaction resultant is applied $\left(r_{I C R} \in\right] r_{q} ; \infty[)$. The rotation considered (clockwise) is opposite to the one assumed in the first mechanism. The kinematics of this mechanism allows a failure mode without activation of the bottom reinforcement (when the instantaneous center of rotation is located at the same level), which, as will be later shown, may govern in some cases. As for mechanism M1, also mechanism M2 allows a failure mode which corresponds to a shift of the outer portion of the footing, without dissipation of energy in the bottom and top reinforcements. This situation occurs when the radius of the instantaneous center of rotation moves toward infinite $\left(r_{I C R} \rightarrow \infty\right)$, leading again to the solution originally proposed by Braestrup et al. [28].

The rate of external work and the components of the rate of internal energy dissipated can be computed for each mechanism based on the velocity field occurring along the failure surface, which is a function of the geometry of this surface and of the location of the instantaneous center of rotation. An example of a failure mechanism and its velocity field is shown in Fig. 6 for mechanisms (a) M1 and (b) M2. As shown in Fig. 6, the velocity $\dot{u}$ along the failure surface may be expressed as:

$\dot{u}=\sqrt{\left(r-r_{I C R}\right)^{2}+\left(z-z_{I C R}\right)^{2}} \cdot \dot{\psi}$

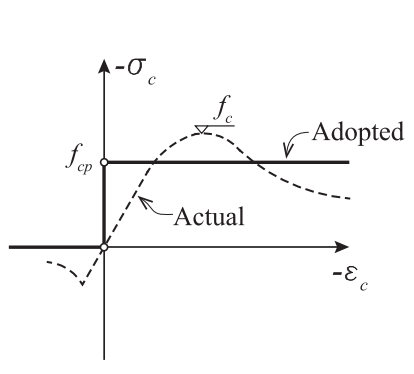

(a)

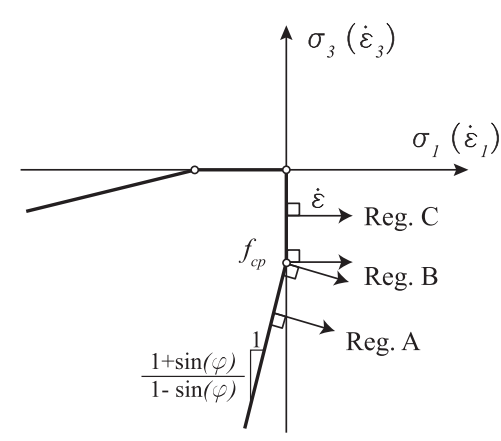

(b)

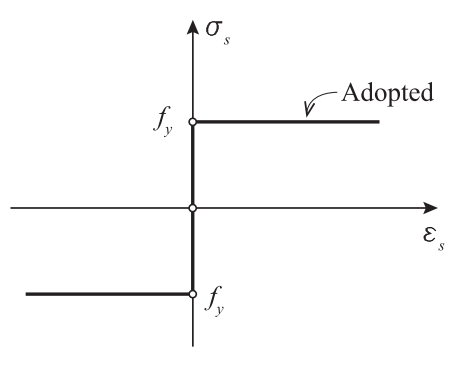

(c)

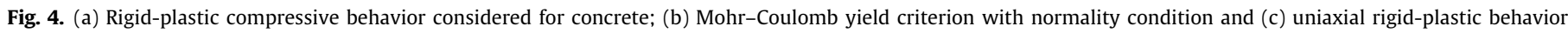
under tension and compression admitted for reinforcement bars. 


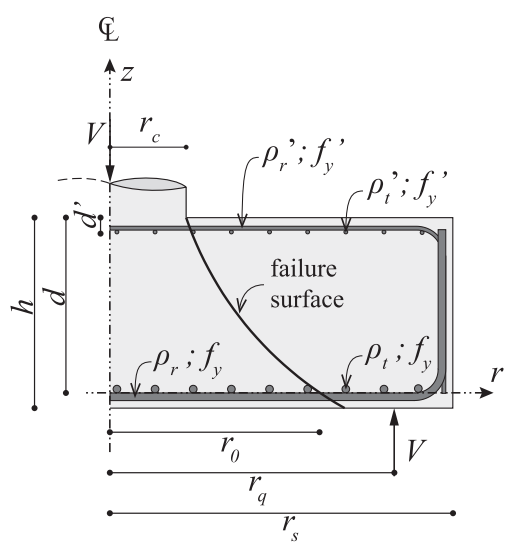

(a)

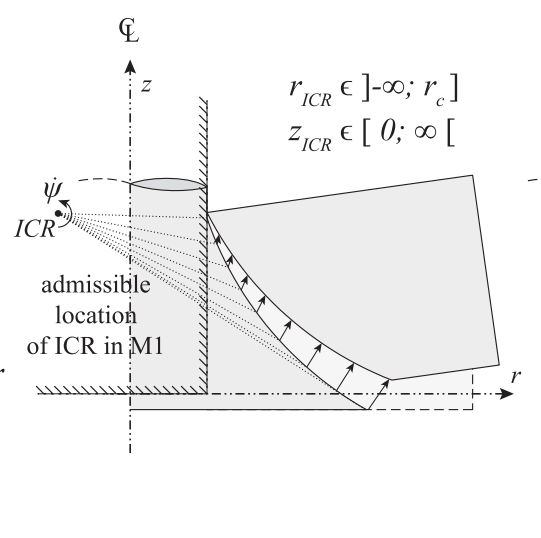

(b)

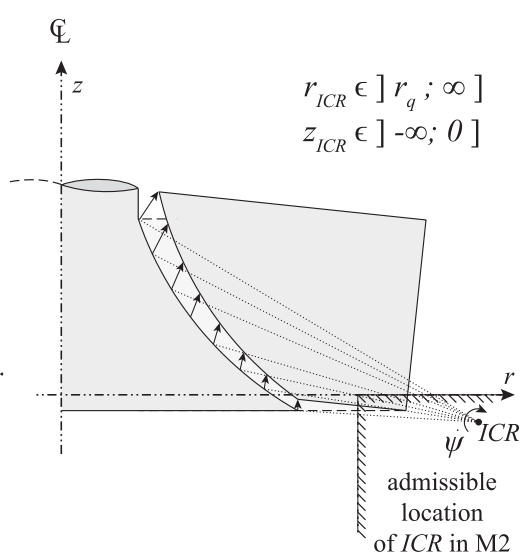

(c)

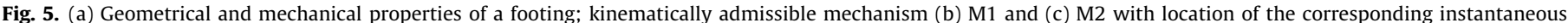
center of rotation (ICR).

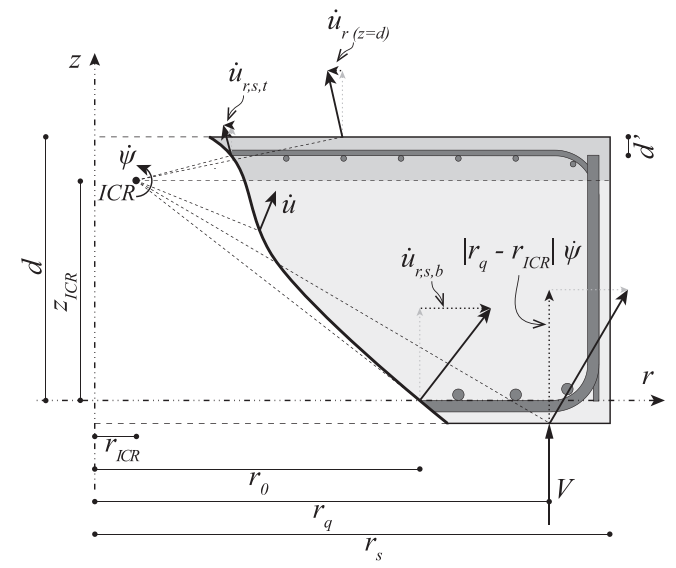

(a)

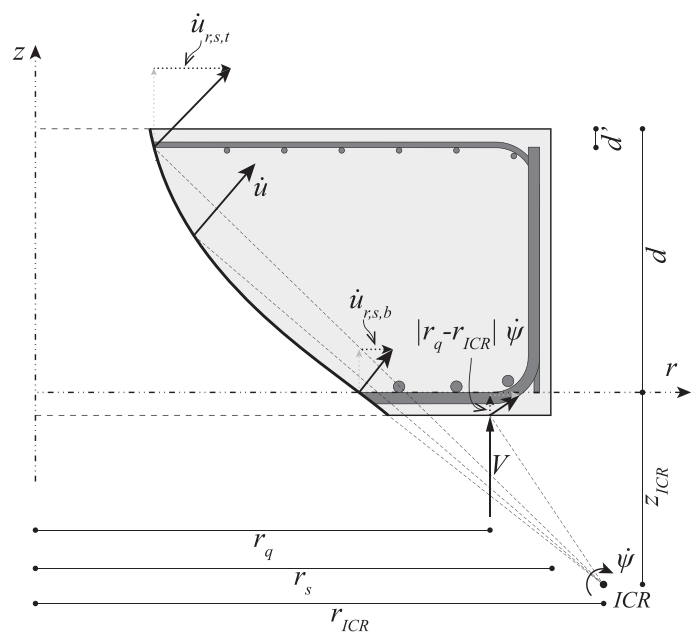

(b)

Fig. 6. Example of mechanisms (a) M1 and (b) M2 and corresponding velocities.

being its radial component $\dot{u}_{r}$ given by:

$\dot{u}_{r}=\left|z-z_{I C R}\right| \cdot \dot{\psi}$

where $r$ and $z$ represent the radial and the height coordinates, respectively. While the reaction resultant applied to the footing provides the only component of the external work, different components of dissipation of internal energy might be activated: (i) shear transfer along the failure surface, (ii) compression in the concrete near top surface in the outer portion due to tangential bending, (iii) bottom and top reinforcements. For a given location of the instantaneous center of rotation $\left(r_{I C R}, z_{I C R}\right)$ and for an assumed geometry of the failure surface, each component of the rate of external work and of the rate of internal energy dissipated may be computed as detailed in the following sections.

\subsection{Rate of external work}

The rate of external work $P_{e}$ is given by:

$P_{e}=V \cdot\left|r_{q}-r_{I C R}\right| \cdot \dot{\psi}$

where the shear force $V$ corresponds to the soil reaction applied to the footing outside the failure surface and $r_{q}$ describes the location of the soil reaction resultant (Fig. 6). In the cases of uniform soil reaction, the total load $Q$ is obtained considering also the soil reaction inside the failure surface:

$Q=V \frac{r_{s}^{2}}{r_{s}^{2}-r_{0}^{2}}$

where $r_{0}$ refers to the radius of the failure surface at the level of the bottom reinforcement. In the present work, it is considered that the failure surface develops between the top surface and the bottom reinforcement (i.e. the cover of the bottom reinforcement is neglected). The radius $r_{q}$ may be calculated by means of:

$r_{q}=\frac{\int_{0}^{2 \pi} \int_{r_{0}}^{r_{s}} r \cdot(r \cdot d r \cdot d \vartheta)}{\int_{0}^{2 \pi} \int_{r_{0}}^{r_{s}} r \cdot d r \cdot d \vartheta}=\frac{2}{3} \frac{\left(r_{s}^{3}-r_{0}^{3}\right)}{\left(r_{s}^{2}-r_{0}^{2}\right)}$

In some tests, or in the case of pile caps, the reaction is concentrated at $r_{q}$ and $Q=V$. While for uniform soil reaction cases, the failure surface may reach the bottom surface in between the edge of the column and the edge of the footing, in the cases of concentrated reactions, the failure surface may only be located in between the edge of the column and the inner radius of the loading areas (considering that supports are rigid). 
2.2. Rate of internal energy dissipated in the concrete along the failure surface

The energy dissipated along the failure surface is one of the components contributing to the total rate of internal energy dissipated in both mechanisms (Fig. 7). The calculation of this component was already investigated by several researchers [e.g. 27,28,31,32,34,45]. This dissipation of energy occurs in a narrow plastic zone with a thickness $\Delta$. The dissipation of energy along the failure surface can be analyzed considering an infinitesimal part of it and assuming a velocity field as the one represented in Fig. 7(b), where a radial view of the plastic zone that develops in the failure surface is shown. As derived in the Appendix A, the rate of internal energy dissipated along the failure surface $P_{i, c, F S}$ may be computed as:

$$
\begin{aligned}
P_{i, c, F S}= & -\pi \cdot f_{c p} \cdot \dot{\psi} \cdot \int_{0}^{d}[\sin (\chi)-1] \cdot \sqrt{\left(r-r_{I C R}\right)^{2}+\left(z-z_{I C R}\right)^{2}} \\
& \cdot \frac{r}{\cos (\alpha)} d z
\end{aligned}
$$

where $\alpha$ refers to the angle between the failure surface and the vertical axis; $\chi$ represents the angle between the failure surface and the velocity. Depending on this latter angle, three different regimes of dissipation of energy, corresponding to the regimes shown in Fig. 4 (b), may occur. In Regime A, which represents a sliding failure, the angle between the failure surface and the velocity is equal to the concrete friction angle $(\chi=\varphi)$, corresponding to the regime where dissipation of energy is maximum. In this case, the geometry of the failure surface generatrix is a logarithmic spiral, since it is known that the angle between the normalized vector tangent to the failure surface generatrix at a certain point, and the normalized vector connecting this point and the instantaneous center of rotation has to be equal to the complementary angle of the concrete friction angle. It can be noted that if the instantaneous center of rotation moves toward infinity, the geometry of the failure surface generatrix in Regime A becomes a straight line. In Regime B, the angle between the failure surface and the velocity is in between the concrete friction angle and $90^{\circ}$. The last regime corresponds to the case where the velocity is normal to the failure surface, which is the reason why it is called as separation failure. In the latter case, neglecting the concrete tensile strength, there is no dissipation of energy. The geometry of the failure surface generatrix in Regime $C$ is known to be a straight line, as the normalized vector tangent to the failure surface at a certain point has to be equal to the normalized vector that connects the same point and the instantaneous center of rotation.

\subsection{Rate of internal energy dissipated in the concrete due to tangential compression}

As can be seen in Fig. 6(a), for mechanism M1, when the instantaneous center of rotation is inside the slab in terms of height $\left(0<z_{I C R}<d\right)$, and only in this case, tangential compression in the concrete in the outer portion of the footing occurs. This component of dissipation of energy is zero in mechanism M2, since its kinematics does not allow the development of tangential compression in the concrete. The tangential compression near the top surface in a footing sector is represented in Fig. 8. It is shown in Appendix B that the rate of internal energy dissipated corresponding to this component is given by:

$P_{i, c, t}=\pi \cdot\left(r_{s}-r_{c}\right) \cdot\left\langle d-z_{I C R}\right\rangle^{2} \cdot f_{c p} \cdot \dot{\psi}$

where $\left\langle d-z_{I C R}\right\rangle$ is equal to zero when the component $d-z_{I C R}$ is negative, corresponding therefore to the cases where there is no compression in the concrete due to tangential bending of the outer portion of the footing.

\subsection{Rate of internal energy dissipated in the reinforcement}

When the failure mechanism considers a velocity field with a non-zero radial component at the level of the reinforcement, dissipation of energy occurs in both radial and tangential directions. For mechanism M1, the bottom reinforcement is considered to be in tension, while the top reinforcement may be in tension or compression, depending upon the location of the instantaneous center of rotation (above or below the top reinforcement, respectively). In mechanism M2, both reinforcements are in tension. The rate of internal energy dissipated in bottom $\left(P_{i, s, b}\right)$ and top reinforcements $\left(P_{i, s, t}\right)$ are derived in the Appendix $C$, being shown to be respectively given by:

$$
\begin{aligned}
P_{i, s, b}= & 2 \cdot \pi \cdot d \cdot f_{c p} \cdot\left[r_{0} \cdot \omega_{r}+\left(r_{s}-r_{0}\right) \cdot \omega_{t}\right] \cdot\left|z_{I C R}\right| \cdot \dot{\psi} \\
P_{i, s, t}= & 2 \cdot \pi \cdot d \cdot f_{c p} \cdot\left[r_{c} \cdot \omega_{r}+\left(r_{s}-r_{c}\right) \cdot \omega_{t}\right] \cdot\left|z_{I C R}-(d-d)\right| \\
& \cdot \dot{\psi}
\end{aligned}
$$

where $\omega_{r}$ and $\omega_{r}^{\prime}$ are respectively bottom and top mechanical reinforcement ratios in radial direction; $\omega_{t}$ and $\omega_{t}^{\prime}$ are respectively bottom and top mechanical reinforcement ratios in tangential direction; being given in a general manner by $\omega=\rho \cdot f_{y} / f_{c p}$. For simplicity, it is considered here that the radial reinforcement ratio is constant along the radius.

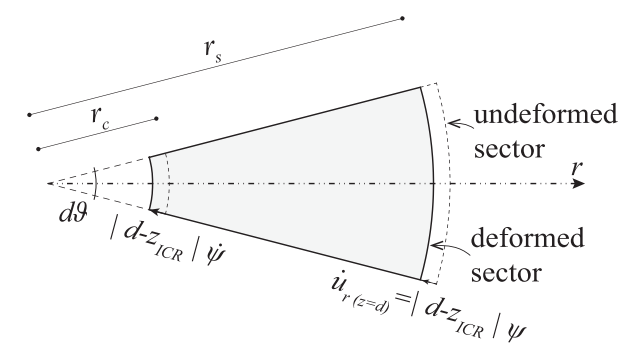

Fig. 8. Top view of footing sector representing the concrete tangential compression.

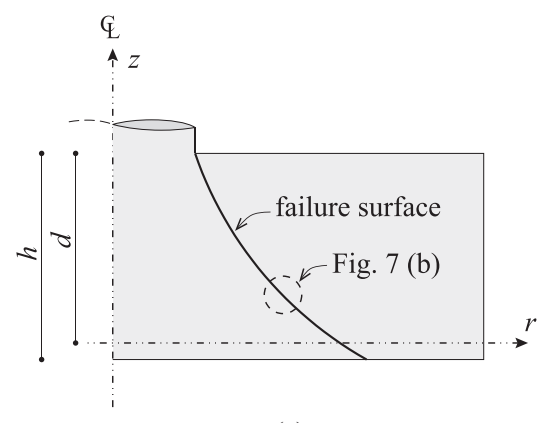

(a)

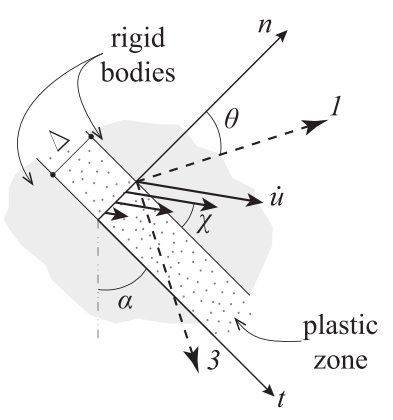

(b)

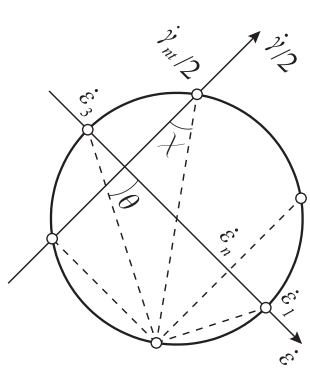

(c)

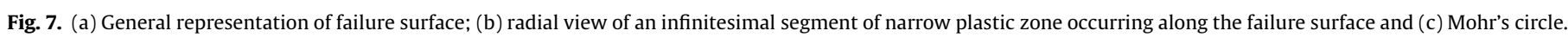




\subsection{Determination of the failure load}

The rate of work equation states that the rate of external work has to be equal to the total rate of internal energy dissipated as: $P_{e}=P_{i}$ (according to the convention followed in $[43,45]$ ). The rate of the external work (given by Eq. (8)) and each component of the total rate of internal energy dissipated (Eqs. (11)-(14)) are nonnegative scalars.

The solution to the problem (location of the instantaneous center of rotation and geometry of the failure surface) results from the minimization of the failure load. As shown in Braestrup et al. [28], the generatrix of the failure surface in the Regime $B$ can be found by calculus of variations, using Lagrange-Euler equations [50]. Alternatively, the problem may also be solved numerically, dividing the failure surface in a finite number of segments, and searching for both the location of the instantaneous center of rotation and the geometry of the failure surface that lead to the lowest load carrying capacity. This corresponds to a constrained non-linear optimization problem, since the location of the instantaneous center of rotation as well as the angle between the failure surface and the velocity are constrained. In the following, results will be presented solved by means of a numerical optimization of the geometry of the failure surface and the location of the instantaneous center of rotation.

\section{Influence of different parameters on the load carrying capacity}

In this section, the results given by the optimization of the proposed kinematical approach are presented and the influence of the most important parameters is investigated. The results presented in this section consider: (i) uniformly distributed soil reaction applied to bottom surface; (ii) equal reinforcement ratio in both radial and tangential directions for bottom and top reinforcements $\left(\rho=\rho_{r}=\rho_{t}\right.$ and $\left.\rho^{\prime}=\rho_{r}^{\prime}=\rho_{t}^{\prime}\right)$ and (iii) effective depth of top reinforcement equal to $d^{\prime}=0.1 \cdot d$. The remaining parameters are the footing (parameter $r_{s} / d$ ) and column sizes (parameter $r_{c} / d$ ), as well as the bottom $\left(\omega=\rho \cdot f_{y} / f_{c p}\right)$ and the top $\left(\omega^{\prime}=\rho^{\prime} \cdot f_{y}^{\prime} / f_{c p}\right)$ mechanical reinforcement ratios. The load carrying capacity is normalized using the concrete plastic compressive strength $\left(f_{c p}\right)$ and the square of the effective depth $(d)$.

\subsection{Governing failure mechanisms}

Fig. 9(a) depicts the relationship between the normalized load carrying capacity and the bottom mechanical reinforcement ratio, considering both mechanisms, for a case having as parameters $r_{s} / d=2.0, r_{c} / d=0.5$ and without top reinforcement $\left(\omega^{\prime}=0\right)$. In the same figure, also the flexural capacity computed based on the yield line pattern shown in Fig. 10 is presented:

$Q_{\text {flex }}=2 \cdot \pi \cdot m_{R} \cdot \frac{r_{s}}{r_{q}-r_{c}} \cdot \frac{r_{s}^{2}}{r_{s}^{2}-r_{c}^{2}}$

where $r_{s}^{2} /\left(r_{s}^{2}-r_{c}^{2}\right)$ is introduced in order to consider the uniform soil reaction under the column and $r_{q}$ is given by Eq. (10) using $r_{0}=r_{c}$. The moment capacity of the section $m_{R}$, which depends upon the location of the neutral axis (above, below or at the level of the top reinforcement), is calculated again assuming a rigidplastic behavior for concrete and steel:

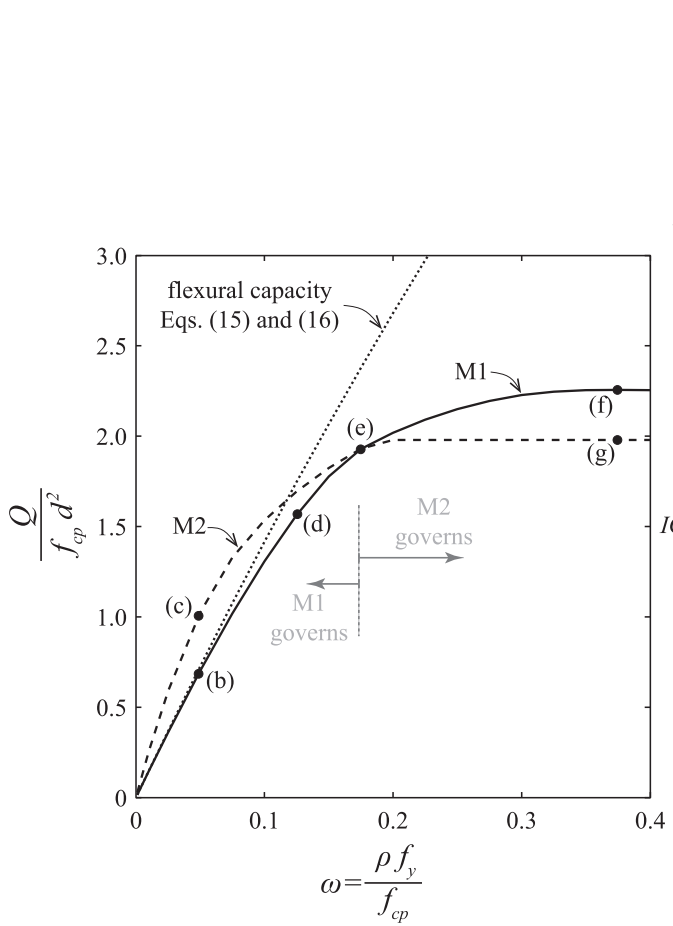

(a)

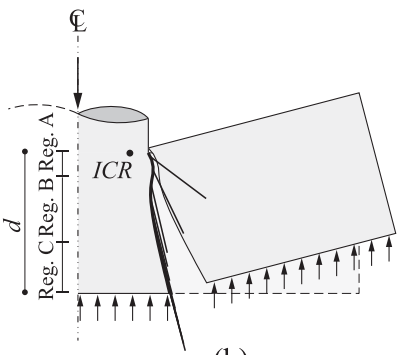

(b)

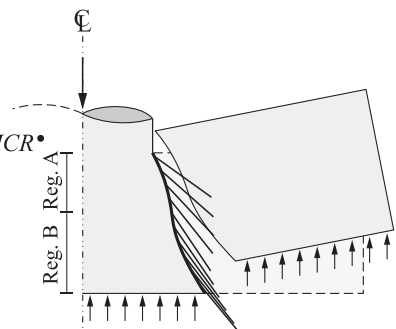

(d)

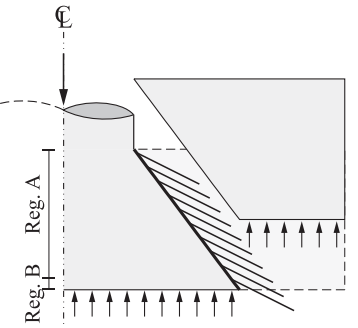

(f)

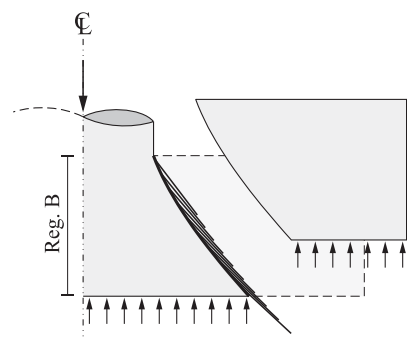

(c)

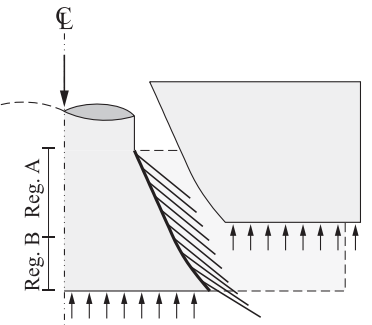

(e)

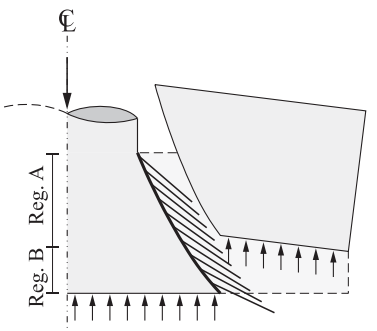

(g)

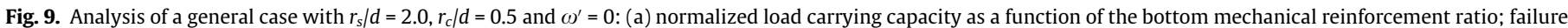

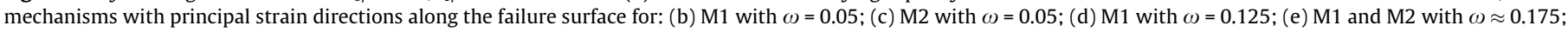
(f) M1 with $\omega=0.375$ and (g) M2 with $\omega=0.375$. 


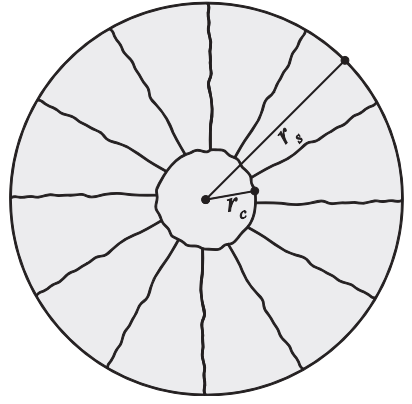

Fig. 10. Yield line pattern considered in flexural failure of a circular footing with a circular column. where the instantaneous center of rotation is in the infinite and the failure mechanism corresponds to a pure translational movement with a horizontal component (Fig. 9(e)). For increasing values of the bottom mechanical reinforcement ratio, mechanism M1 leads to a reduction of the horizontal component of this translational movement, until the failure mechanism consists only in a vertical shift of the outer portion of the footing (Fig. 9(f)). This process is characterized by a decrease of the dissipation of energy in the bottom reinforcement, as a consequence of the decrease of the radial component of the velocity. This reduction is accompanied by an increase of the energy dissipated along the failure surface, which results from the increment of the length of Regime $A$ along the failure surface (compare Fig. 9(e) and (f)). However, as

$$
m_{R}= \begin{cases}f_{c p} \cdot\left(\omega+\omega^{\prime}\right) \cdot d \cdot\left(d^{\prime}-\frac{c}{2}\right)+\omega \cdot f_{c p} \cdot d \cdot\left(d-d^{\prime}\right) \text { with } c=d \cdot\left(\omega+\omega^{\prime}\right), & \text { if } \omega+\omega^{\prime}<d^{\prime} / d \\ f_{c p} \cdot\left(\omega-\omega^{\prime}\right) \cdot d \cdot\left(d^{\prime}-\frac{c}{2}\right)+\omega^{\prime} \cdot f_{c p} \cdot d \cdot\left(d-d^{\prime}\right) \text { with } c=d \cdot\left(\omega-\omega^{\prime}\right), & \text { if } \omega-\omega^{\prime}>d^{\prime} / d \\ f_{c p} \cdot d \cdot\left(\frac{d^{\prime 2}}{2 \cdot d}+\omega \cdot\left(d-d^{\prime}\right)\right), & \text { otherwise }\end{cases}
$$

Fig. 9(b)-(g) present several failure mechanisms for the cases highlighted in Fig. 9(a), representing mechanisms M1 and M2. The principal strain directions along the failure surface (computed using Eq. (A.8)), which represent the principal direction of the compression, are also represented.

A clear flexural failure mode is shown to occur only for fairly low amounts of bottom mechanical reinforcement ratio (refer to Fig. 9 (a)), where the load carrying capacity given by mechanism M1 is very close to the flexural capacity computed using Eq. (15). As shown in Fig. 9(a), mechanism M1 is governing for low amounts of bottom mechanical reinforcement ratio, defining a transition between flexural and punching shear failures. In fact, mechanism M1 considers in its kinematics the rotation known to occur for a flexural failure (Fig. 9(b)). On the contrary, mechanism M2 considers a clockwise rotation, therefore leading to a failure mechanism more related to a translational movement (associated to punching failures) during the flexural-shear failure regime (Fig. 9(c)). While for mechanism M1, the instantaneous center of rotation is close to the column, thus leading to an important component of rotation, in mechanism M2, the instantaneous center of rotation is far from it, leading to a dominant translational movement with low rotation associated. Therefore, in mechanism M1 (Fig. 9(b)), a steep failure surface with biaxial compression (Regime A) close to the top surface, and a separation failure (Regime C) without dissipation of energy, close to the bottom surface, is observed. Hence, in mechanism M1, a considerably amount of the rate of internal energy dissipated occurs in the bottom reinforcement due to the important component of rotation in its failure mode. This is the reason why an increase of the bottom mechanical reinforcement leads to a significant increase in the load carrying capacity, accompanied by a reduction of the rotation component. For higher values of the bottom mechanical reinforcement ratio, the significance of the rotation decreases, reducing the influence of the bottom reinforcement. At this point, the dissipation of energy in the concrete along the failure surface increases, and the biaxially compressed zone extends toward the bottom surface. The evolution of the described process regarding mechanism M1 may be observed with the help of Fig. 9 (b), (d) and (e), where it is possible to follow the decrease of the rotation component and the growth of the importance of Regime A along the failure surface.

The transition between mechanisms M1 and M2 occurs when the rotation component disappears. This corresponds to the case it can be observed in Fig. 9(a), for fairly large values of the bottom mechanical reinforcement ratio, this solution does not correspond to the lowest upper bound solution, since another failure mechanism is governing. The failure mechanism governing in this case, represented in Fig. 9(g), includes an important rotation component contrary to the one normally considered in a flexural failure. In this failure mechanism, the instantaneous center of rotation is located close to the footing and at the level of the bottom reinforcement, thus not activating it. From the comparison of Fig. 9(f) and (g), respectively, corresponding to failure mechanisms M1 and M2 for equal bottom mechanical reinforcement ratio, it is possible to observe that the second mechanism leads to a lower contribution of the biaxially compressed zone (Regime A).

\subsection{Parametric analysis}

The results presented in Fig. 9 are extended in Fig. 11 for several cases varying the footing size (ratio $r_{s} / d=1.5 ; 2.25 ; 3.0$ ), the column size (ratio $r_{c} / d=0.2 ; 0.4 ; 0.6$ ), as well as the top mechanical reinforcement ratio $\left(\omega^{\prime}=0 ; 0.05\right)$. In Fig. 11 is also shown the normalized flexural capacity, computed according to Eqs. (15) and (16). Although the influence of the ratios $r_{s} / d, r_{c} / d$ and $\omega^{\prime}$ is important, the evolution of the normalized load carrying capacity with the bottom mechanical reinforcement ratio presented for the general case of Fig. 9, is also observed in all the cases shown in Fig. 11.

Although the influence of top mechanical reinforcement ratio (when reasonable values of it are adopted) tends to be reduced in the cases where mechanism M1 is governing, it shows a considerably influence in the results where mechanism M2 governs. This influence may be observed comparing Fig. 11(a)-(c) with Fig. 11 (d)-(f), respectively, where the consideration of a low amount of top mechanical reinforcement ratio $\left(\omega^{\prime}=0.05\right)$ leads to a significant increase of the load carrying capacity.

A large value of top mechanical reinforcement ratio leads to a limit situation corresponding to the instantaneous center of rotation located at infinite in the radial axis, thus leading to a failure mode characterized by a vertical movement of the outer portion of the footing. In this case, both mechanism M1 and M2 lead to the same failure mechanism and load carrying capacity, which corresponds to the solution originally proposed by Braestrup et al. [28]. This phenomenon may be observed, for example, comparing 


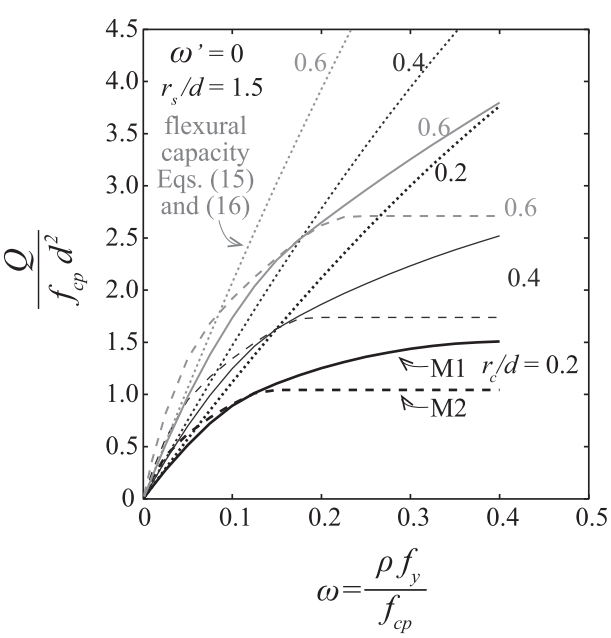

(a)

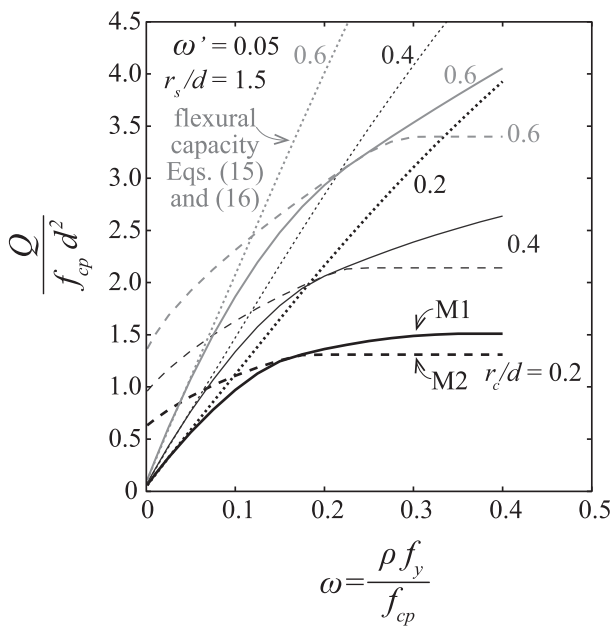

(d)

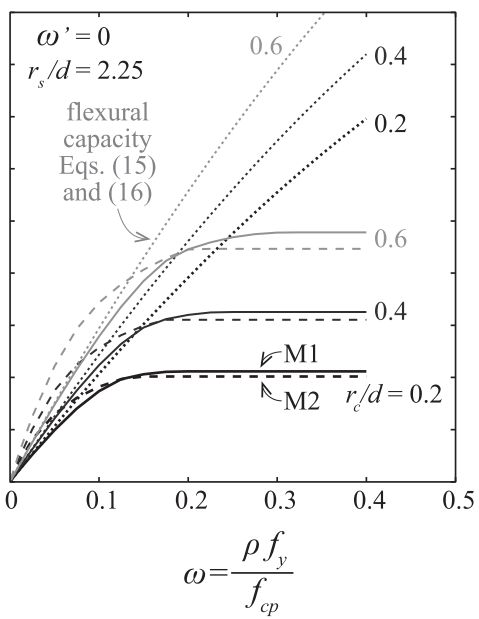

(b)

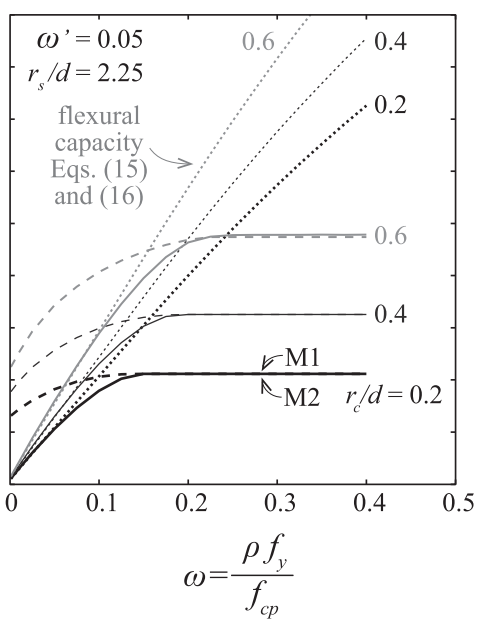

(e)

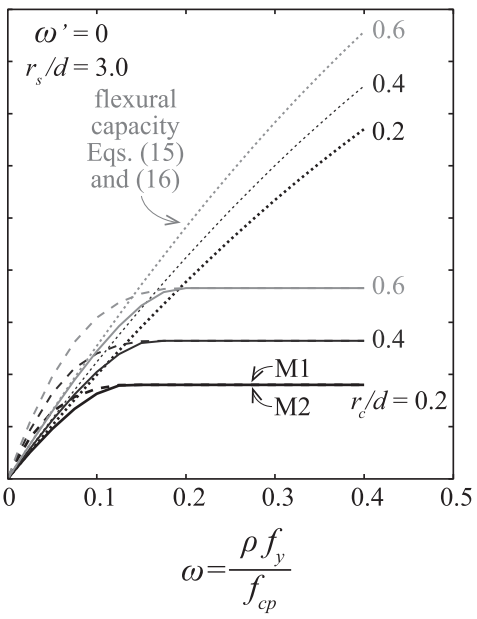

(c)

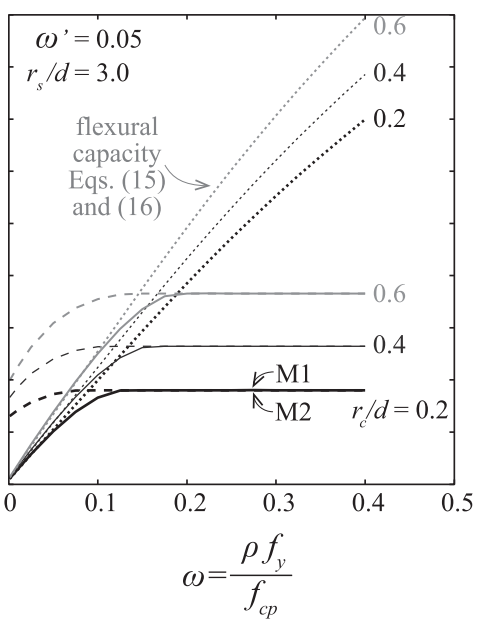

(f)

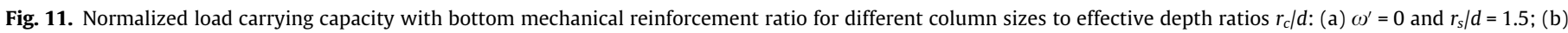
$\omega^{\prime}=0$ and $r_{s} / d=2.25$; (c) $\omega^{\prime}=0$ and $r_{s} / d=3.0$; (d) $\omega^{\prime}=0.05$ and $r_{s} / d=1.5$; (e) $\omega^{\prime}=0.05$ and $r_{s} / d=2.25$; (f) $\omega^{\prime}=0.05$ and $r_{s} / d=3.0$.

the case of $r_{s} / d=2.25$ and $r_{c} / d=0.4$ presented in Fig. 11 (b) and (d). An increase of the punching shear strength with the increase of the top mechanical reinforcement ratio is related to a decrease of the rotation component and to the increase of the biaxially compressed zone along the failure surface. This is the kinematical reason why the top reinforcement becomes more efficient for more compact slabs and larger column sizes, since these are the cases where a larger clockwise rotation component in the punching shear regime exists (mechanism M2 governing, compare e.g. Fig. 11(a) and (c)). It is interesting to note that although this conclusion is obtained through a kinematical approach, it is physically consistent with the fact that the development of confinement stresses, due to the presence of top reinforcement, enables the improvement of the capacity of the diagonal compression strut carrying shear that develops inside the footing [51].

With respect to the ratio of the column size (ratio $r_{c} / d$ ), it may be observed that for larger column sizes, although the failure surface is slightly steeper, not only the radius of the failure surface at the level of the bottom reinforcement, but also the area of the failure surface is larger, leading to a higher load carrying capacity.

As shown in Fig. 11, and as previously explained, the punching shear strength increases with increasing column size, with increasing top mechanical reinforcement ratio and with decreasing footing size. As a consequence, the flexural-shear regime becomes more important, covering a larger range of bottom mechanical reinforcement ratios, meaning that this regime is relevant for the analysis of footings.

Although the presented analysis has been carried for uniform soil reaction, it may also be performed for concentrated reactions, leading to the same general conclusions. In these cases, as observed by Braestrup et al. [28], when concrete tensile strength is neglected, as in the present work, the failure surface develops between the column and the inner radius of the support, accounting for the size of the loading areas (necessary to distribute the reaction forces).

\section{Simplified formulations - practical application}

The application in the practice of the kinematical approach above presented would be time consuming. For this reason, the development of simplified expressions, allowing a simpler, yet accurate, calculation of the load carrying capacity of footings becomes important. The application of the expressions that will be presented in the following is limited to the cases of footings (i) without shear reinforcement, (ii) considered to be subjected to a uniform soil reaction and (iii) with $r_{c} / d \leqslant 1.2,1.0 \leqslant a / d \leqslant 3.0$ 
(where $a=r_{s}-r_{c}$ ) and $2.0 \leqslant r_{s} / r_{c} \leqslant 12.0$. For simplicity reasons, only cases without top reinforcement will be investigated. This consideration is sufficiently approximated for practical purposes as the top reinforcement does not yield to significant differences except for very compact members with large columns (refer to Fig. 11).

In accordance to what is presented in the previous section, two different regimes are considered: flexural-shear regime for low amounts of bottom mechanical reinforcement ratio and punching shear regime for large amounts of the same parameter.

\subsection{Flexural-shear failures}

It was previously shown that this regime, where an interaction between flexural and shear behavior is observed, leads to lower load carrying capacity than the one predicted considering a flexural failure with the yield pattern shown in Fig. 10 (Eqs. (15) and (16)). In fact, a flexural failure considers a compression zone resulting from a pure flexural behavior, thus being only a function of the bottom and top mechanical reinforcement ratios (Eq. (16)). However, this does not occur for compact footings subjected to a concentrated load. In these cases, a concentration of large shear forces near the column is observed, resulting from a compression strut whose radial force component equilibrates most of the force of the whole tension reinforcement. For this reason, the height of the compression zone in the radial direction is significantly larger than in the tangential direction. For cases without shear reinforcement as those treated in this paper, the latter can even disappear as the instantaneous center of rotation is located outside the footing.

Due to the inclination of the actual compression strut carrying shear and the location of its resultant, the effective lever arm is reduced with respect to the one corresponding to a flexural analysis (Fig. 12(b)). The location of the resultant of the compression strut at the edge of the column $\left(z_{c}\right.$ in Fig. 12(a)) can be calculated on the basis of the results of the optimized theoretical solution using equilibrium conditions, as the load carrying capacity and the reinforcement forces are known. A good estimation of these results is given by the following equation:

$\frac{z_{c}}{d}=\frac{\omega}{2} \cdot\left(1+0.4 \cdot \frac{r_{s}}{r_{c}} \cdot \frac{d}{r_{q}-r_{c}}\right)$ where $r_{q}$ is calculated using Eq. (10) with $r_{0}=r_{c}$. The load carrying capacity $Q_{f s}$ can thus be calculated according to Eq. (15) but using a reduced moment capacity $\bar{m}_{R}$ accounting for the reduced lever arm, defined as:

$\bar{m}_{R}=f_{c p} \cdot d^{2} \cdot \omega \cdot\left(1-\frac{z_{c}}{d}\right)$ with $z_{c} / d$ from Eq. (17)

It has to be noted that this equation is valid only for the flexuralshear failure as yielding of bottom reinforcement is assumed. For large amounts of bottom reinforcement, pure shear regime becomes governing.

\subsection{Punching shear failures}

Considering that sufficient amount of bottom flexural reinforcement is used to avoid a flexural-shear failure, a punching shear failure without plastic activation of the flexural reinforcement governs. In this regime, the load carrying capacity relies only on the internal energy dissipated by the concrete along the failure surface. Thus, a nominal control section where an effective shear stress is to be verified helps investigating this regime (typical approach of design codes). The location of this control section has to be a function of the inclination of the failure surface as well as of the distribution of the internal energy dissipated along the failure surface. A steeper inclination of the failure surface as well as a higher concentration of the energy dissipated near the column requires a control section closer to it. Besides being important to define the location of a nominal control section, the inclination of the failure surface is also important to define the amount of uniform soil reaction that acts inside the failure zone.

Fig. 13 depicts the secant inclination $\beta$ of the failure surface as a function of the shear slenderness ratio $a / d$, for different values of the column size to effective depth ratio $r_{c} / d$. This inclination is defined as:

$\cot (\beta)=\frac{r_{0}-r_{c}}{d}$

It is shown in Fig. 13 that this inclination is mostly a function of the shear slenderness (it decreases with increasing of the shear slenderness). This is in accordance with different experimental evidences [e.g. 14,15,17,18], which have shown a relationship

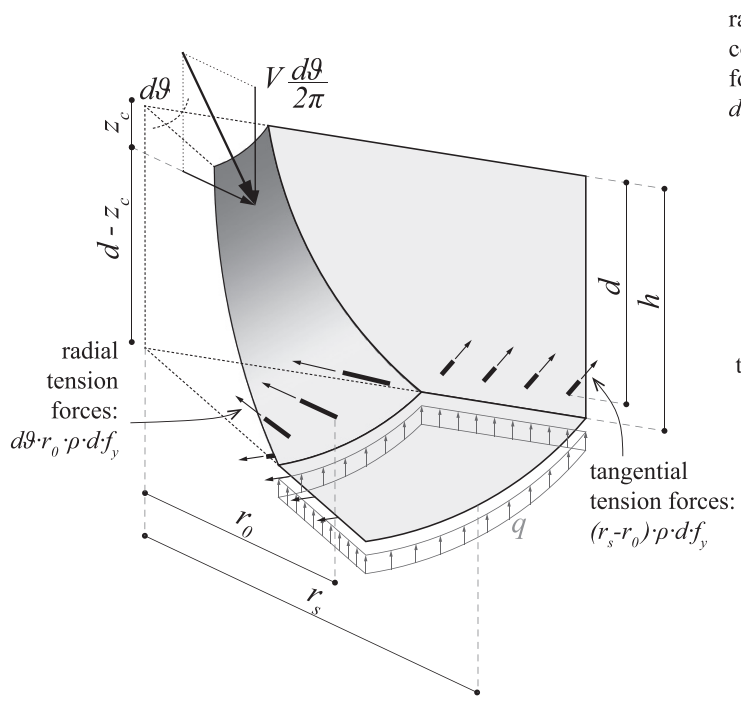

(a)

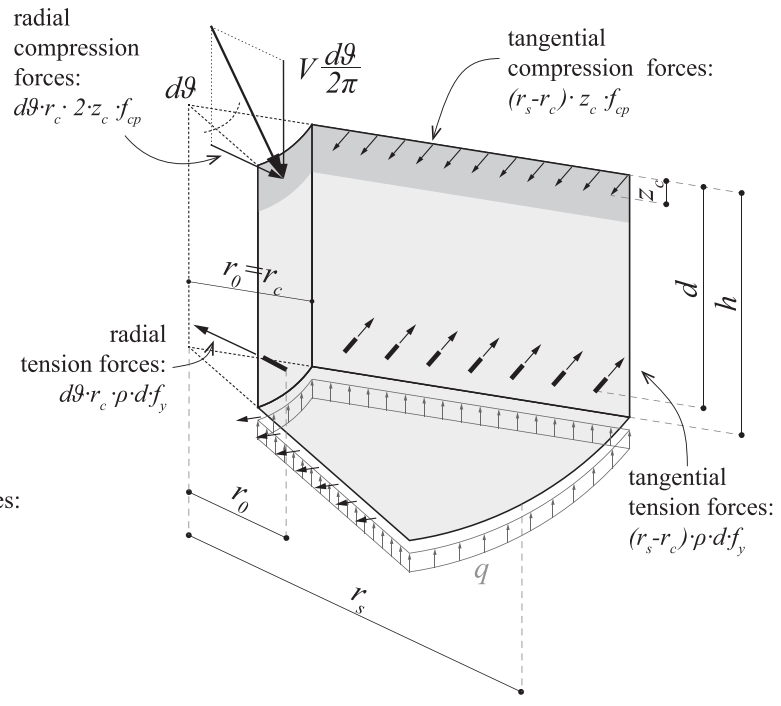

(b)

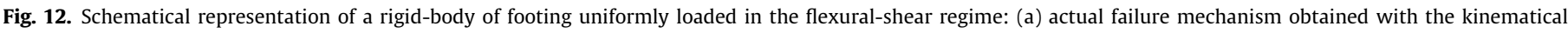
theorem of limit analysis and (b) failure mechanism considered in the calculation of the flexural-shear capacity through the simplified formulation. 


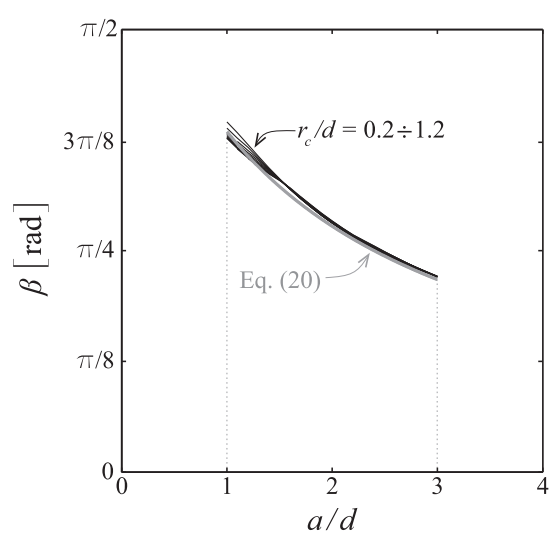

(a)

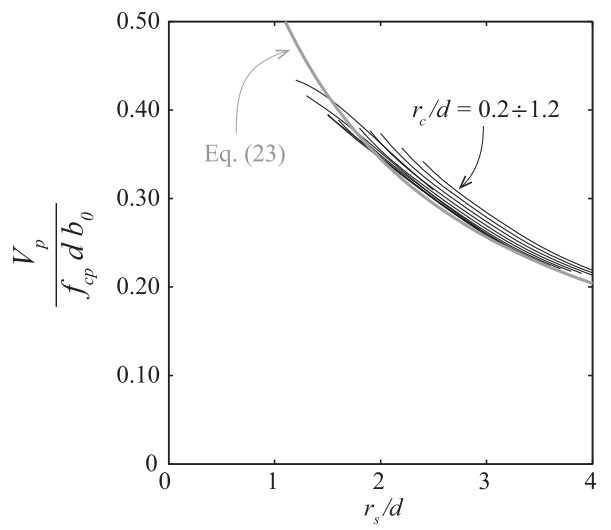

(b)

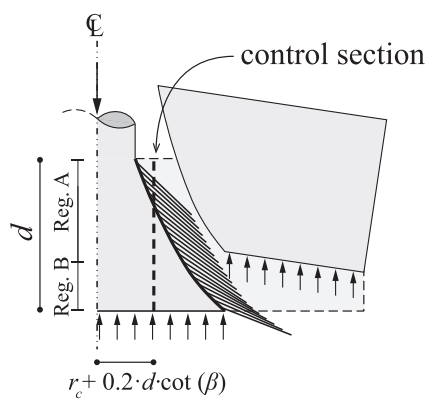

(c)

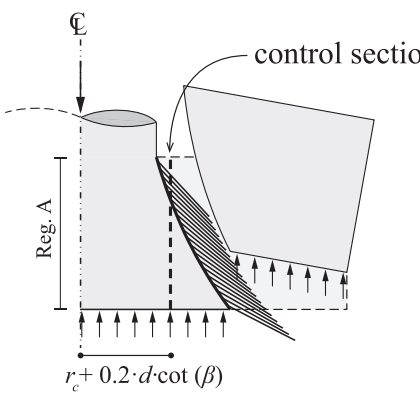

(d)

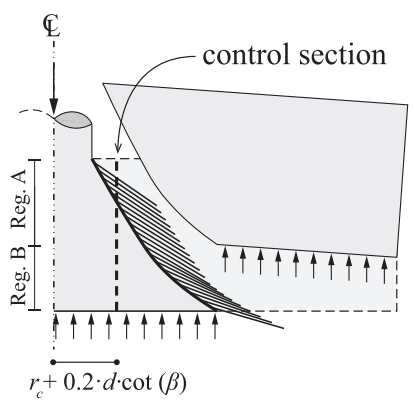

(e)

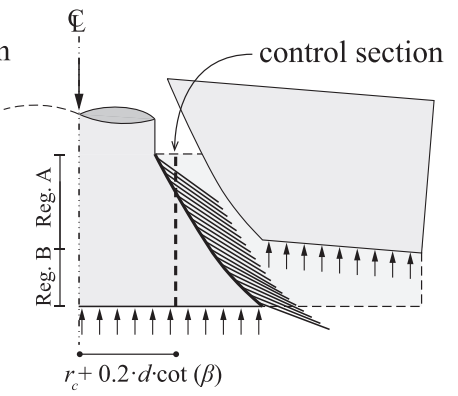

(f)

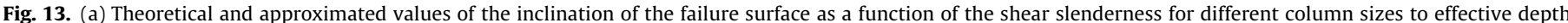

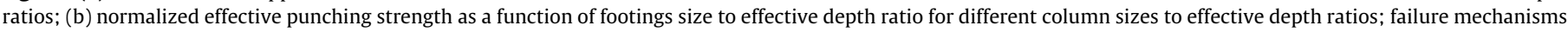

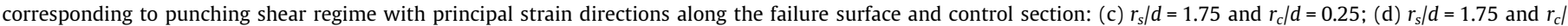
$d=0.50$; (e) $r_{s} / d=2.25$ and $r_{c} / d=0.25$; (f) $r_{s} / d=2.25$ and $r_{c} / d=0.50$.

between the inclination of the shear crack of the punching cone and the shear slenderness, with stepper shear cracks observed for more compact footings. Based on the results of the kinematical approach herein presented, a simple formula for the secant inclination $\beta$ can be proposed:

$\beta=\frac{\pi / 2}{0.8+0.5 \cdot \frac{a}{d}}[\mathrm{rad}]$

Based on this inclination, the radius of the failure surface $r_{0}$ at level of the bottom reinforcement can be calculated according to Eq. (19). On that basis, it is also possible to define the part of the uniform soil reaction acting inside the failure zone (and thus do not influencing the shear strength) and the total load carrying capacity $Q_{p}$ corresponding to this regime:

$Q_{p}=V_{p} \cdot \frac{r_{s}^{2}}{r_{s}^{2}-r_{0}^{2}}$

where $V_{p}$ represents the effective shear strength in the case of punching shear regime, thus corresponding to the uniform soil reaction outside the radius of the failure surface at the level of bottom reinforcement. Based on the column radius as well as on the radius of the failure surface at the level of the bottom reinforcement, a control section and its corresponding perimeter $b_{0}$ may be defined as:

$b_{0}=2 \cdot \pi \cdot\left[r_{c}+0.2 \cdot d \cdot \cot (\beta)\right]$

Parameter 0.2 defines a control section located at $0.2 \cdot d \cdot \cot (\beta)$ from the column edge. This choice is justified by the curvature of the failure surface with a steeper inclination near the column, precisely where a concentration of energy dissipation tends to occur (see Fig. 13(c)-(f)).

The punching shear carrying capacity, normalized by the plastic concrete compressive strength $f_{c p}$ and by the control section $b_{0} \cdot d$, is shown as a function of the footing size in Fig. 13(b) for different column sizes. The figure shows that the normalized effective punching shear strength is mostly a function of the footing size to effective depth ratio $r_{s} / d$. An increase of this parameter leads to a decrease of the normalized effective punching load, which is in accordance to what is physically expected. A simplified expression can be proposed to calculate the normalized effective punching strength as a function of the footing size to effective depth ratio:

$V_{p}=\frac{1}{0.9+\frac{r_{s}}{d}} \cdot f_{c p} \cdot b_{0} \cdot d$

It can be noted that $f_{c p}$ is calculated using Eq. (1) to account for concrete brittleness and the presence of transverse strains. The results obtained with the proposed expression are also shown in Fig. 13(b), approximating fairly well the results numerically obtained through the optimization of the kinematical approach above presented.

The lowest failure load obtained by the simplified expressions proposed for each regime is the governing load carrying capacity. A general comparison of the normalized load capacity obtained through the optimized solution of the kinematical approach above presented and the proposed simplified expressions is presented in Fig. 14, for different footing and column sizes (span to effective 


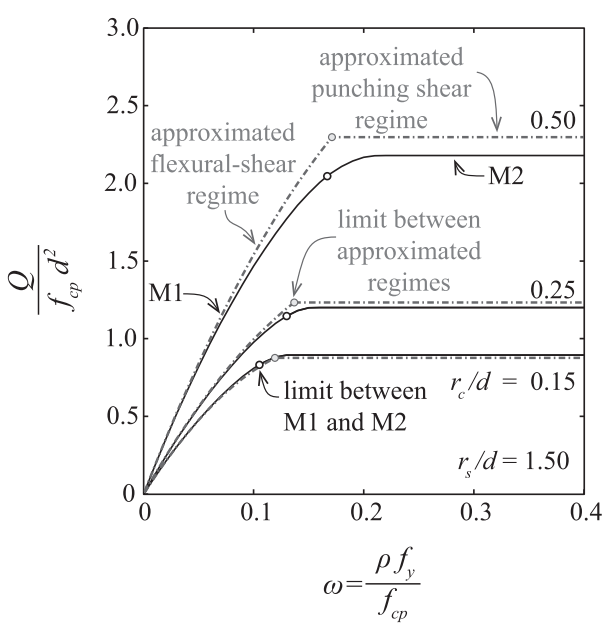

(a)

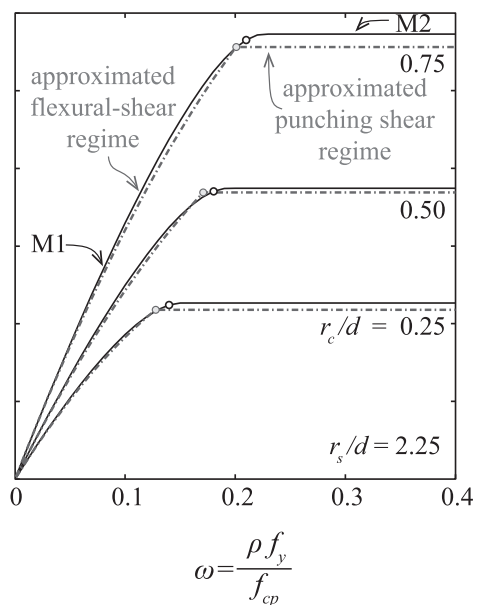

(b)

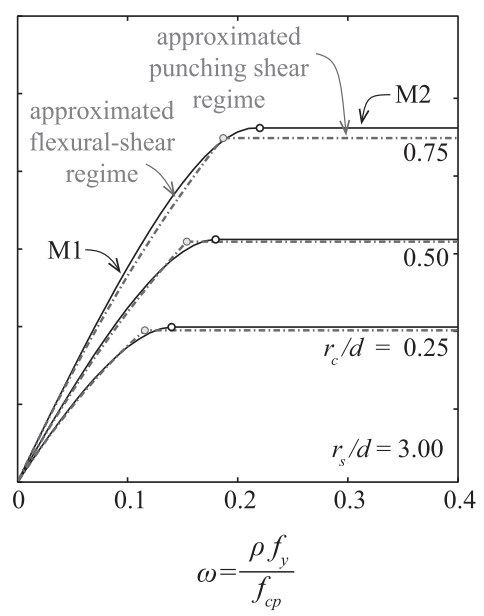

(c)

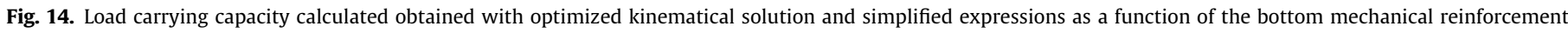
ratio for different column sizes to effective depth ratios: (a) $r_{s} / d=1.50$; (b) $r_{s} / d=2.25$ and (c) $r_{s} / d=3.0$.

depth ratio $a / d$ varying from to 1.0 to 2.9 ). A very good agreement of the optimized kinematical solution by the proposed expressions can be observed.

\section{Comparison with experimental results}

Several experimental investigations concerning the punching shear strength of footings have been performed in the past [e.g. $1,2,4,5,7,9,11-18]$. The experimental investigations presented by Hallgren et al. [7] and Dieterle and Rostásy [5] are particularly interesting, since both testing campaigns contained several tests with the same loading conditions and where all the parameters $\left(r_{s}, r_{c}, r_{q}, d, \omega^{\prime}\right)$ were kept approximately constant, only varying the bottom mechanical reinforcement ratio $\omega$. The parameters selected to compare the theoretical solution with the experimental values represent average values of the experimental tests considered in the comparison (the main properties of each experimental test are shown in Table 1, where a circular column with an equal perimeter of a rectangular column was considered and, in the case of square footings, $r_{s}$ was calculated considering an equal area for the bottom surface). The plastic concrete compressive strength was calculated according to Eq. (1) considering a constant value for the reduction factor accounting for the presence of transverse strains $\eta_{\varepsilon}$. Actually, this factor is not constant within the group of experimental tests considered, since it is a function of the state of strains in the region of the theoretical failure surface [47-49], therefore depending on the bottom mechanical reinforcement ratio. Higher values of the latter ratio are associated to lower transverse strains. For this reason, two different values of the reduction factor accounting for the presence of transverse strains are considered in the comparison between the experimental results of Hallgren et al. [7] and the theoretical values of the normalized load carrying capacity, computed based on the optimization of the kinematical solution, shown in Fig. 15 (a) $\eta_{\varepsilon}=0.5$ and (b) $\eta_{\varepsilon}=0.6$. These values are in agreement with the reductions factors usually adopted for concrete with shear cracks $[45,49,52]$. The results

Table 1

Description of experimental tests performed by Hallgren et al. [7] and Dieterle and Rostásy [5].

\begin{tabular}{|c|c|c|c|c|c|c|c|c|c|c|}
\hline Source & Specimen & Footing's shape & $r_{s}^{\mathrm{a}}[\mathrm{mm}]$ & Column's shape & $r_{c}^{\mathrm{b}}[\mathrm{mm}]$ & $d[\mathrm{~mm}]$ & $f_{c, \text { cube }}{ }^{\mathrm{c}}[\mathrm{MPa}]$ & $\rho^{\mathrm{d}}[\%]$ & $f_{y}[\mathrm{MPa}]$ & $V_{R, \text { test }}[\mathrm{MN}]$ \\
\hline \multirow[t]{9}{*}{ Hallgren et al. [7] $]^{\mathrm{e}}$} & $\mathrm{S} 1$ & \multirow{7}{*}{ Square } & \multirow{7}{*}{480} & \multirow{9}{*}{ Circular } & \multirow{9}{*}{125} & 242 & 49.8 & 0.40 & \multirow[t]{9}{*}{621} & 1.363 \\
\hline & $\mathrm{S} 2$ & & & & & 243 & 35.5 & 0.40 & & 1.015 \\
\hline & S3 & & & & & 250 & 37.2 & 0.39 & & 1.008 \\
\hline & S4 & & & & & 232 & 32.1 & 0.66 & & 0.992 \\
\hline & S7 & & & & & 246 & 18.0 & 0.40 & & 0.622 \\
\hline & S8 & & & & & 245 & 39.3 & 0.25 & & 0.915 \\
\hline & S9 & & & & & 244 & 31.9 & 0.40 & & 0.904 \\
\hline & $\mathrm{S} 12$ & \multirow{2}{*}{ Circular } & \multirow{2}{*}{480} & & & 242 & 34.1 & 0.42 & & 1.049 \\
\hline & S13 & & & & & 244 & 24.7 & 0.42 & & 0.803 \\
\hline \multirow[t]{8}{*}{ Dieterle and Rostásy [5] } & B-1 & \multirow{8}{*}{ Square } & \multirow{8}{*}{846} & \multirow{8}{*}{ Square } & \multirow{8}{*}{191} & 296 & 28.2 & 0.20 & 453 & 1.054 \\
\hline & B-2 & & & & & 294 & 28.4 & 0.42 & 451 & 1.522 \\
\hline & B-3 & & & & & 293 & 33.8 & 0.62 & 415 & 2.065 \\
\hline & B-4 & & & & & 292 & 28.9 & 0.83 & 395 & 1.902 \\
\hline & B- $4 / 2$ & & & & & 290 & 30.4 & 0.89 & 458 & 2.090 \\
\hline & $B-4 / 3$ & & & & & 294 & 29.2 & 0.86 & 464 & 2.068 \\
\hline & B-4/4 & & & & & 292 & 29.8 & 0.83 & 395 & 1.889 \\
\hline & V2 & & & & & 294 & 33.0 & 0.40 & 486 & 1.800 \\
\hline
\end{tabular}

\footnotetext{
a In the case of square footings, $r_{s}$ is calculated considering an equal area for the bottom surface.

b In the case of square columns, $r_{c}$ is computed assuming an equal column perimeter.

c To compare with the theoretical results, an $f_{c}=0.8 f_{c, \text { cube }}$ is considered.

d The reinforcement ratio was considered equal in both radial and tangential directions; its value was assumed to be equal to the average reinforcement ratio determined in orthogonal direction.

e For the square footings of Hallgren et al. [7], $r_{q}$ is simplified considering to be equal to the one of the experimental tests in circular footings ( $r_{q}=337$ mm).
} 


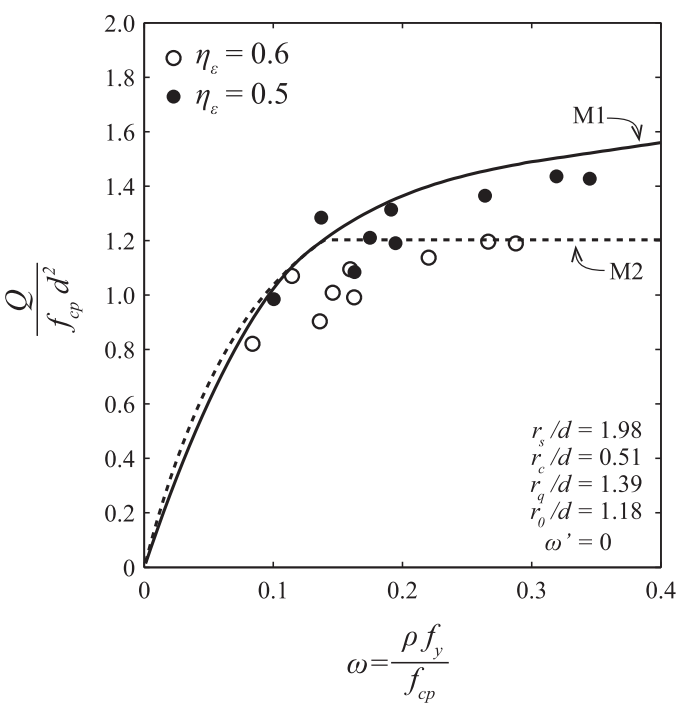

(a)

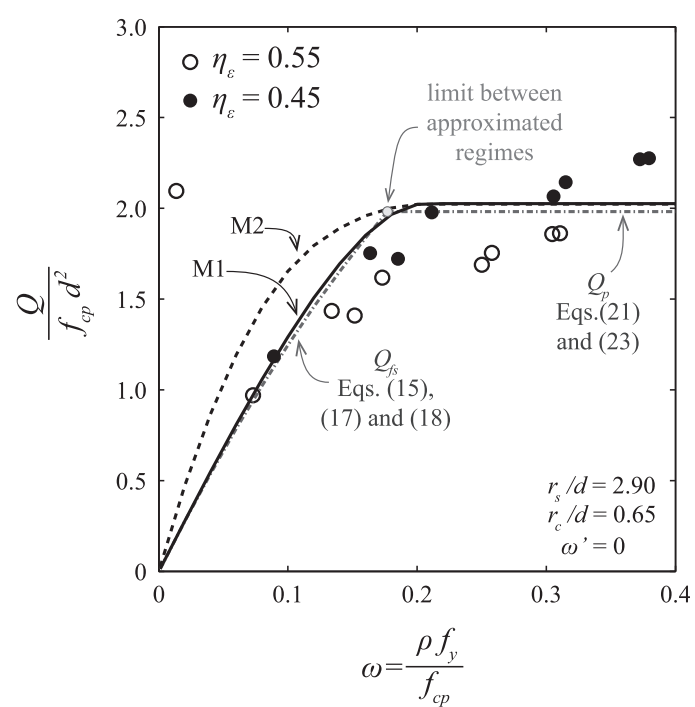

(b)

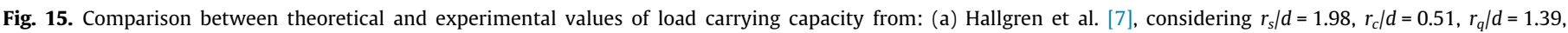
$r_{0} / d=1.18$ and $\omega^{\prime}=0$; (b) Dieterle and Rostásy [5] considering $r_{s} / d=2.90, r_{c} / d=0.65$ and $\omega^{\prime}=0$.

show a fairly good agreement between theory and experimental results. It is interesting to note that the test results with lower amounts of bottom mechanical reinforcement ratio approximate better the theoretical results for smaller values of the reduction factor $\eta_{\varepsilon}$. On the contrary, for the footings with larger amounts of bottom mechanical reinforcement ratio, a better agreement is found (and thus smaller strains at failure) if a higher value is considered for the reduction factor $\eta_{\varepsilon}$.

Fig. 15(b) shows a comparison with the tests performed by Dieterle and Rostásy [5] (main properties shown in Table 1). According to the authors of the experimental campaign, the four tests with $\rho>0.8 \%$ presented a bond failure at the plane of the bottom flexural reinforcement, leading to a potentially premature punching shear failure. Nevertheless, it is not clear if bond failure was the cause of a premature punching failure or was just a consequence of punching. For that reason, the referred experimental tests are also considered herein. For this group of tests, a reduction factor accounting for the presence of transverse strains $\eta_{\varepsilon}$ varying within 0.45 and 0.55 is considered (slightly lower than for the previous series). The different range of values considered for each group of experimental tests may be justified by the different geometrical and material properties, as well as different loading conditions and potential bond failures. As this group of experimental tests was conducted with a uniform loading applied to the bottom surface of the footings, the simplified expressions are also presented in Fig. 15(b) approximating very well the optimized solution of the kinematical approach of limit analysis.

Although the comparisons between experimental results and theoretical values have shown a fairly good agreement for both groups of experimental tests, it remains clear that the value of the reduction factor $\eta_{\varepsilon}$ to be applied in order to take into account the state of strains has to be further investigated. In addition, the potential influence of size is also a topic of future works.

\section{Conclusions}

The kinematical theorem of limit analysis is used in order to determine the load carrying capacity of isolated footings subjected to concentrated loads. The concrete is considered to have rigid-plastic behavior with a Mohr-Coulomb yield criterion.
A rigid-plastic behavior in both compression and tension is also adopted for the reinforcement bars. The influence of each physical parameter in the load carrying capacity based on the proposed approach is assessed. The main conclusions are:

1. Pure flexural failure only occurs for fairly low amounts of bottom mechanical reinforcement, while pure punching shear failure results only for large amounts of flexural reinforcement;

2. For intermediate amounts of flexural reinforcement, a combined flexural-shear mechanism becomes governing, allowing a smooth transition between flexural and punching shear failure modes. It is shown that this regime is particularly important for compact footings and larger columns, thus showing its importance when predicting the load carrying capacity of footings;

3. In what respects the punching shear regime, it is shown that the consideration of a failure characterized by a translational vertical movement of the outer portion of the footing might overestimate the punching shear strength in the cases of low amounts of top mechanical reinforcement ratios. This difference is more important for compact footings and for larger column sizes. In these cases, the top reinforcement ratio might play an important role;

4. A physical explanation for the previous conclusion on the influence of the top reinforcement, is that this reinforcement enables the development of confining stresses along the failure surface, increasing the capacity of the compression strut that carries shear directly inside the footing;

5. Simplified formulations for practical use are presented for the cases of footings subjected to uniform soil reaction, incorporating simplified expressions that allow the calculation of the load carrying capacity corresponding to each regime. It is shown that the simplified formulations proposed approximate fairly well the optimized kinematical solution;

6. The lower load capacity observed in the flexural-shear regime, when compared to the pure flexural capacity, is explained by the loss of lever arm due to the increase of the compression height at the column edge, where both shear and radial compression are carried by an inclined compression strut. This shows that the Johansen's yield line theory [24] developed for thin slabs is not really applicable for compact footings. 
7. In what respects the punching shear regime, it is shown that the inclination of the failure surface is mostly a function of the shear slenderness and that the control section for assessing the shear strength should be located rather close to the column (closer than values usually adopted for punching design of flat slabs). This is justified by the fact that the failure surface presents, in a wide range of cases, a curved geometry with a steeper inclination close to the column, precisely where an important amount of internal energy is dissipated;

8. The proposed plastic approach is shown to approximate fairly well the experimental results of Hallgren et al. [7] and Dieterle and Rosásty [5];

9. Further investigation remains to be done regarding the value of the reduction factor that takes into account the state of transverse strains of the footings on the concrete strength and potentially also size effect.

\section{Appendix A}

This appendix describes the calculation of the rate of internal energy dissipated in the concrete along the failure surface. This dissipation of energy is investigated considering an infinitesimal region of the plastic zone occurring along the failure surface and assuming a velocity field as the one represented in Fig. 7(b), where a radial view of this plastic zone is shown. Tangential and normal velocities as well as tangential, normal and deviatoric strains rates in this radial plane are respectively defined as:

$\dot{u}_{t}=\frac{n}{\Delta} \cdot \dot{u} \cdot \cos (\chi)$

$\dot{u}_{n}=\frac{n}{\Delta} \cdot \dot{u} \cdot \sin (\chi)$

$\dot{\varepsilon}_{t}=\frac{\partial \dot{u}_{t}}{\partial t}=0$

$\dot{\varepsilon}_{n}=\frac{\partial \dot{u}_{n}}{\partial n}=\frac{\dot{u}}{\Delta} \cdot \sin (\chi)$

$\dot{\gamma}_{n t}=\frac{\partial \dot{u}_{t}}{\partial n}+\frac{\partial \dot{u}_{n}}{\partial t}=\frac{\dot{u}}{\Delta} \cdot \cos (\chi)$

where $\dot{u}$ is the velocity (Eq. (6)) and $\chi$ is the angle between the velocity and the failure surface (refer to Fig. 7). As shown in Fig. 7 (c), based on Mohr's circle, the principal strains rates $\dot{\varepsilon}_{1}$ and $\dot{\varepsilon}_{3}$, as well as the principal directions $\theta$ an be respectively determined by:

$$
\begin{aligned}
\dot{\varepsilon}_{1} & =\frac{\dot{u}}{2 \cdot \Delta} \cdot \sin (\chi)+\sqrt{\frac{\dot{u}^{2}}{4 \cdot \Delta^{2}}\left[\sin (\chi)^{2}+\cos (\chi)^{2}\right]} \\
& =\frac{\dot{u}}{2 \cdot \Delta} \cdot[\sin (\chi)+1] \\
\dot{\varepsilon}_{3} & =\frac{\dot{u}}{2 \cdot \Delta} \cdot \sin (\chi)-\sqrt{\frac{\dot{u}^{2}}{4 \cdot \Delta^{2}}\left[\sin (\chi)^{2}+\cos (\chi)^{2}\right]} \\
& =\frac{\dot{u}}{2 \cdot \Delta} \cdot[\sin (\chi)-1]
\end{aligned}
$$

$\tan (2 \cdot \theta)=\frac{\cos (\chi)}{\sin (\chi)}=\cot (\chi)=\tan \left(\frac{\pi}{2}-\chi\right) \Rightarrow \theta=\frac{\pi}{4}-\frac{\chi}{2}$

With respect to $\dot{\varepsilon}_{2}$, it varies linearly in the thickness of the plastic zone from zero (inner region) to the value of the tangential strain rate in the outer portion of the footing. Due to the fact that the thickness of the plastic zone is negligible with respect to the volume of the outer portion of the footing, the rate of internal energy dissipated in the plastic zone due to $\dot{\varepsilon}_{2}$ can be neglected. Using the relations defined in Eqs. (3)-(5) for the rigid-plastic behavior considered for the concrete (refer to Fig. 4(b)), the rate of internal energy dissipated per unit of failure surface area $d P_{i, c, F S}$ for the three different regimes can be computed as:

$$
\begin{aligned}
d P_{i, c, F S} & =\left(\dot{\varepsilon}_{1} \cdot \sigma_{1}+\dot{\varepsilon}_{3} \cdot \sigma_{3}\right) \cdot \Delta \cdot d A \\
& =\frac{\dot{u}}{2} \cdot[\sin (\chi)+1] \cdot \sigma_{1} \cdot d A+\frac{\dot{u}}{2} \cdot[\sin (\chi)-1] \cdot \sigma_{3} \cdot d A \\
& =-\frac{1}{2} \cdot f_{c p} \cdot[\sin (\chi)-1] \cdot \sqrt{\left(r-r_{I C R}\right)^{2}+\left(z-z_{I C R}\right)^{2}} \cdot \dot{\psi} \cdot d A
\end{aligned}
$$

The rate of internal energy dissipated along the failure surface $P_{i, c, F S}$ is therefore determined by:

$P_{i, c, F S}=\int d P_{i, c, F S}$

being the unit of area defined by:

$d A=r \cdot d \vartheta \cdot \frac{d z}{\cos (\alpha)}$

where $\alpha$ refers to the angle between the failure surface and the vertical axis. Using Eqs. (A.9) and (A.11), Eq. (A.10) can be rewritten as:

$$
\begin{aligned}
P_{i, c, F S}= & -\int_{0}^{2 \cdot \pi} \int_{0}^{d} \frac{1}{2} \cdot f_{c p} \cdot[\sin (\chi)-1] \cdot \sqrt{\left(r-r_{I C R}\right)^{2}+\left(z-z_{I C R}\right)^{2}} \\
& \cdot \dot{\psi} \cdot \frac{r}{\cos (\alpha)} \cdot d z \cdot d \vartheta \\
= & -\pi \cdot f_{c p} \cdot \dot{\psi} \cdot \int_{0}^{d}[\sin (\chi)-1] \cdot \sqrt{\left(r-r_{I C R}\right)^{2}+\left(z-z_{I C R}\right)^{2}} \\
& \cdot \frac{r}{\cos (\alpha)} \cdot d z
\end{aligned}
$$

\section{Appendix B}

This appendix describes the rate of internal energy dissipated in the concrete due to tangential compression outside the failure surface (deformation of the footing portion outside the failure surface considered to have a conical shape). The strain rate in tangential direction within the compression zone $\left(z_{I C R}<z \leqslant d\right)$ is a function of the radial component of the velocity:

$\dot{\varepsilon}_{c, t}=-\frac{\dot{u}_{r}(z)}{r}=-\frac{\left|z-z_{I C R}\right| \cdot \dot{\psi}}{r}$

where $z$ refers to the coordinate varying along the depth of the compression zone, thus being within $z \in\left[z_{I C R} ; d\right]$. The rate of internal energy dissipated per unit of volume $d P_{i, c, t}$ due to this component given by:

$d P_{i, c, t}=-\dot{\varepsilon}_{c, t} \cdot f_{c p} \cdot d V o l$

Hence, the rate of internal energy dissipated in the concrete due to the tangential compression $P_{i, c, t}$ is defined by:

$P_{i, c, t}=-\int \dot{\varepsilon}_{c, t} \cdot f_{c p} \cdot d V o l$

with

$d V o l=d A \cdot d z=r \cdot d r \cdot d \vartheta \cdot d z$

where $d \vartheta$ represents the angle of a footing sector. Using Eqs. (B.1) (B.2) and (B.4), Eq. (B.3) can be rewritten as: 


$$
\begin{aligned}
P_{i, c, t} & =\int_{z_{I C R}}^{d} \int_{0}^{2 \cdot \pi} \int_{r_{c}}^{r_{s}} \frac{\left|z-z_{I C R}\right|}{r} \cdot f_{c p} \cdot \dot{\psi} \cdot r \cdot d r \cdot d \vartheta \cdot d z \\
& =\int_{z_{I C R}}^{d} \int_{0}^{2 \cdot \pi} \int_{r_{c}}^{r_{s}}\left|z-z_{I C R}\right| \cdot f_{c p} \cdot \dot{\psi} \cdot d r \cdot d \vartheta \cdot d z \\
& =\pi \cdot\left(r_{s}-r_{c}\right) \cdot\left\langle d-z_{I C R}\right\rangle^{2} \cdot f_{c p} \cdot \dot{\psi}
\end{aligned}
$$

where $\left\langle d-z_{I C R}\right\rangle$ is equal to zero when the component $d-z_{I C R}$ is negative. These correspond to the cases where compression due to tangential bending of the outer portion of the footing does not exist.

Alternatively, the same result could be obtained by considering that the continuum tangential deformation of the outer portion is replaced by assuming tangential displacement discontinuities in a number of vertical (radial) failure surfaces where plane stress conditions are assumed.

\section{Appendix C}

This appendix describes the rate of internal energy dissipated in both bottom flexural and top reinforcement when the radial component of the velocity is non-zero. This component of the velocity at the level of the bottom reinforcement $(z=0)$ is given by:

$\dot{u}_{r, s, b}=\dot{u}_{r_{(z=0)}}=\left|z_{I C R}\right| \cdot \dot{\psi}$

being the rate of internal energy dissipated in radial direction per unit of area of bottom radial reinforcement $d P_{i, s, b}^{r a d}$ defined by:

$d P_{i, s, b}^{r a d}=\dot{u}_{r, s, b} \cdot f_{y} \cdot d A_{r, s, b}$

and the corresponding rate of internal energy dissipated $P_{i, s, b}^{\mathrm{rad}}$ is thus given by:

$P_{i, s, b}^{r a d}=\int \dot{u}_{r, s, b} \cdot f_{y} \cdot d A_{r, s, b}$

where the unit of area of bottom radial reinforcement $d A_{r, s, b}$ is determined by:

$d A_{r, s, b}=\rho_{r} \cdot d \cdot r_{0} \cdot d \vartheta$

Replacing Eqs. (C.1), (C.2) and (C.4) in Eq. (C.3), the rate of internal energy dissipated in the bottom reinforcement in the radial direction can be defined as:

$P_{i, s, b}^{r a d}=\int_{0}^{2 \cdot \pi}\left|z_{I C R}\right| \cdot f_{y} \cdot \rho_{r} \cdot d \cdot r_{0} \cdot \dot{\psi} \cdot d \vartheta$

In what respects tangential direction, the corresponding strain rate $\dot{\varepsilon}_{s, b}^{\mathrm{tan}}$ results from the radial component of the velocity at the level of the corresponding reinforcement $(z=0)$ :

$\dot{\varepsilon}_{s, b}^{\tan }=\frac{\dot{u}_{r, s, b}}{r}=\frac{\left|z_{I C R}\right| \cdot \dot{\psi}}{r}$

being the rate of internal energy dissipated per unit of volume of bottom tangential reinforcement $d P_{i, s, b}^{\mathrm{tan}}$ defined by:

$d P_{i, s, b}^{\mathrm{tan}}=\varepsilon_{s, b}^{\mathrm{tan}} \cdot f_{y} \cdot d V o l_{t, s, b}$

where

$d V o l_{t, s, b}=\rho_{t} \cdot d \cdot r \cdot d r \cdot d \vartheta$

The rate of internal energy dissipated in tangential direction $P_{i, s, b}^{\mathrm{tan}}$ is therefore defined by:

$P_{i, s, b}^{\tan }=\int_{0}^{2 \cdot \pi} \int_{r_{0}}^{r_{s}}\left|z_{I C R}\right| \cdot f_{y} \cdot \rho_{t} \cdot d \cdot \dot{\psi} \cdot d r \cdot d \vartheta$
Taken into account the contributions of both radial and tangential directions, defined in Eqs. (C.5) and (C.9), the rate of internal energy dissipated in the bottom reinforcement can be computed as:

$$
\begin{aligned}
P_{i, s, b}= & P_{i, s, b}^{r a d}+P_{i, s, b}^{\mathrm{tan}} \\
= & \int_{0}^{2 \cdot \pi}\left|z_{I C R}\right| \cdot f_{y} \cdot \rho_{r} \cdot d \cdot r_{0} \cdot \dot{\psi} \cdot d \vartheta \\
& +\int_{0}^{2 \cdot \pi} \int_{r_{0}}^{r_{s}}\left|z_{I C R}\right| \cdot f_{y} \cdot \rho_{t} \cdot d \cdot \dot{\psi} \cdot d r \cdot d \vartheta \\
= & 2 \cdot \pi \cdot d \cdot f_{y} \cdot\left[r_{0} \cdot \rho_{r}+\left(r_{s}-r_{0}\right) \cdot \rho_{t}\right] \cdot\left|z_{I C R}\right| \cdot \dot{\psi}
\end{aligned}
$$

Defining respectively the bottom mechanical reinforcement ratio in radial and tangential direction as $\omega_{r}=\rho_{r} \cdot f_{y} / f_{c p}$ and $\omega_{t}=\rho_{t} \cdot f_{y} / f_{c p}$, Eq. (C.10) can be rewritten:

$P_{i, s, b}=2 \cdot \pi \cdot d \cdot f_{c p} \cdot\left[r_{0} \cdot \omega_{r}+\left(r_{s}-r_{0}\right) \cdot \omega_{t}\right] \cdot\left|z_{I C R}\right| \cdot \dot{\psi}$

The rate of internal energy dissipated in the top reinforcement can be computed in an analogous manner as for the bottom reinforcement. Hence, concerning the radial direction, the radial component of the velocity at its level $\dot{u}_{r, s, t}^{\text {rad }}$, the rate of internal energy dissipated per unit of area of top radial reinforcement $d P_{i, s, t}^{r a d}$ and the rate of internal energy dissipated $P_{i, s, t}^{r a d}$ are respectively given by:

$$
\begin{aligned}
& \dot{u}_{r, s, t}=\dot{u}_{r_{\left(z=d-d^{\prime}\right)}}=\left|z_{I C R}-\left(d-d^{\prime}\right)\right| \cdot \dot{\psi} \\
& d P_{i, s, t}^{r a d}=\dot{u}_{r, s, t} \cdot f_{y}^{\prime} \cdot d A_{r, s, t}, \text { with } d A_{r, s, t}=\rho_{r}^{\prime} \cdot d \cdot r_{c} \cdot d \vartheta \\
& P_{i, s, t}^{r a d}=\int_{0}^{2 \cdot \pi}\left|z_{I C R}-(d-d)\right| \cdot f_{y} \cdot \rho_{r} \cdot d \cdot r_{c} \cdot \dot{\psi} \cdot d \vartheta
\end{aligned}
$$

With respect to the tangential direction, the corresponding strain rate $\dot{\varepsilon}_{s, t}^{\text {tan }}$, the rate of internal energy dissipated per unit of volume of top tangential reinforcement $d P_{i, s, t}^{\mathrm{tan}}$ and the rate of internal energy dissipated $P_{i, s, t}^{\mathrm{tan}}$ can be respectively computed as:

$$
\begin{aligned}
& \dot{\varepsilon}_{s, t}^{\tan }=\frac{\dot{u}_{r, s, t}}{r}=\frac{\left|z_{I C R}-\left(d-d^{\prime}\right)\right| \cdot \dot{\psi}}{r} \\
& d P_{i, s, t}^{\tan }=\varepsilon_{s, t}^{\mathrm{tan}} \cdot f_{y}^{\prime} \cdot d V o l_{t, s, t}, \text { with } d V o l_{t, s, t}=\rho_{t}^{\prime} \cdot d \cdot r \cdot d r \cdot d \vartheta \\
& P_{i, s, t}^{\mathrm{tan}}=\int_{0}^{2 \cdot \pi} \int_{r_{c}}^{r_{s}}\left|z_{I C R}-\left(d-d^{\prime}\right)\right| \cdot f_{y}^{\prime} \cdot \rho_{t}^{\prime} \cdot d \cdot \dot{\psi} \cdot d r \cdot d \vartheta
\end{aligned}
$$

The rate of internal energy dissipated in the top reinforcement $P_{i, s, t}^{\mathrm{tan}}$ results from the sum of both tangential and radial components, respectively given by Eqs. (C.14) and (C.17). Taking into account that top mechanical reinforcement ratio in radial and tangential directions are respectively defined by $\omega_{r}^{\prime}=\rho_{r}^{\prime} \cdot f_{y}^{\prime} / f_{c p}$ and $\omega_{t}^{\prime}=\rho_{t}^{\prime} \cdot f_{y}^{\prime} / f_{c p}$, the rate of internal energy dissipated in the top reinforcement may be determined in accordance to Eq. (C.18):

$P_{i, s, t}=2 \cdot \pi \cdot d \cdot f_{c p} \cdot\left[r_{c} \cdot \omega_{r}^{\prime}+\left(r_{s}-r_{c}\right) \cdot \omega_{t}^{\prime}\right] \cdot\left|z_{I C R}-\left(d-d^{\prime}\right)\right| \cdot \dot{\psi}$ 


\section{Appendix D}

\begin{tabular}{|c|c|}
\hline \multicolumn{2}{|l|}{ Notation } \\
\hline$a$ & shear span \\
\hline$b_{0}$ & control perimeter \\
\hline$c$ & height of compression zone \\
\hline$d$ & $\begin{array}{l}\text { effective depth of bottom flexural } \\
\text { reinforcement }\end{array}$ \\
\hline$d^{\prime}$ & effective depth of top reinforcement \\
\hline$d A$ & unit of failure surface area \\
\hline$d A_{r, s, b}, d A_{r, s, t}$ & $\begin{array}{l}\text { unit of area of bottom and top radial } \\
\text { reinforcement }\end{array}$ \\
\hline$d V o l$ & unit of volume \\
\hline$d \operatorname{Vol}_{t, s, b}, d \operatorname{Vol}_{t, s, t}$ & $\begin{array}{l}\text { unit of volume of bottom and top tangential } \\
\text { reinforcement }\end{array}$ \\
\hline$d P_{i, c, F S}$ & $\begin{array}{l}\text { rate of internal energy dissipated in the } \\
\text { concrete per unit of failure surface area }\end{array}$ \\
\hline$d P_{i, c, t}$ & $\begin{array}{l}\text { rate of internal energy dissipated in the } \\
\text { concrete per unit of area due to tangential } \\
\text { bending }\end{array}$ \\
\hline$d P_{i, s, b}^{\tan }, d P_{i, s, t}^{\tan }$ & $\begin{array}{l}\text { rate of internal energy dissipated in the } \\
\text { bottom and top reinforcement per unit of } \\
\text { reinforcement area in the tangential } \\
\text { direction }\end{array}$ \\
\hline$d P_{i, s, b}^{r a d}, d P_{i, s, t}^{r a d}$ & $\begin{array}{l}\text { rate of internal energy dissipated in the } \\
\text { bottom and top reinforcement per unit of } \\
\text { reinforcement area in the radial direction }\end{array}$ \\
\hline$d \vartheta$ & angle of a footing sector \\
\hline$f_{c}$ & cylinder concrete compressive strength \\
\hline$f_{c 0}$ & reference compressive strength \\
\hline$f_{c, \text { cube }}$ & cube concrete compressive strength \\
\hline$f_{c p}$ & plastic concrete compressive strength \\
\hline$f_{y}$ & yield stress of bottom steel reinforcement \\
\hline$f_{y}^{\prime}$ & yield stress of top steel reinforcement \\
\hline$h$ & height of the footing \\
\hline$m_{R}$ & moment capacity per unit of length \\
\hline $\bar{m}_{R}$ & reduced moment capacity per unit of length \\
\hline$n, t$ & normal and tangential directions in Fig. 7 \\
\hline$P_{e}$ & rate of external work \\
\hline$P_{i}$ & total rate of internal energy dissipated \\
\hline$P_{i, c, F S}$ & $\begin{array}{l}\text { rate of internal energy dissipated in the } \\
\text { concrete along the failure surface }\end{array}$ \\
\hline$P_{i, c, t}$ & $\begin{array}{l}\text { rate of internal energy dissipated in the } \\
\text { concrete due to tangential bending }\end{array}$ \\
\hline$P_{i, s, b}, P_{i, s, t}$ & $\begin{array}{l}\text { rate of internal energy dissipated in the } \\
\text { bottom and top reinforcements }\end{array}$ \\
\hline$P_{i, s, b}^{r a d}, P_{i, s, b}^{\tan }$ & $\begin{array}{l}\text { rate of internal energy dissipated in bottom } \\
\text { reinforcement in radial and tangential } \\
\text { directions }\end{array}$ \\
\hline$P_{i, s, t}^{r a d}, P_{i, s, t}^{\tan }$ & $\begin{array}{l}\text { rate of internal energy dissipated in the top } \\
\text { reinforcement in radial and tangential } \\
\text { directions }\end{array}$ \\
\hline$q$ & uniform soil pressure \\
\hline$Q$ & total load carrying capacity \\
\hline$Q_{\text {flex }}$ & flexural capacity \\
\hline$Q_{f s}$ & flexural-shear capacity \\
\hline$Q_{p}$ & punching shear capacity \\
\hline$r$ & radial coordinate \\
\hline$r_{c}$ & radius of a circular column \\
\hline$r_{I C R}$ & $\begin{array}{l}\text { radial coordinate of the instantaneous } \\
\text { center of rotation }\end{array}$ \\
\hline$r_{q}$ & radius of the reaction resultant \\
\hline
\end{tabular}

\begin{tabular}{|c|c|}
\hline$r_{s}$ & radius of circular footing \\
\hline$r_{0}$ & $\begin{array}{l}\text { radius of the failure surface at the level of } \\
\text { the bottom flexural reinforcement }\end{array}$ \\
\hline$\dot{u}$ & velocity \\
\hline$\dot{u}_{n}$ & normal velocity \\
\hline$\dot{u}_{t}$ & tangential velocity \\
\hline$\dot{u}_{r}$ & radial component of velocity \\
\hline$\dot{u}_{r, s, b}, \quad \dot{u}_{r, s, t}$ & $\begin{array}{l}\text { radial component of velocity at the level of } \\
\text { the bottom and top reinforcements }\end{array}$ \\
\hline$V$ & load carrying capacity \\
\hline$V_{\text {flex }}$ & effective flexural capacity \\
\hline$V_{f s}$ & effective flexural-shear capacity \\
\hline$V_{p}$ & effective punching shear capacity \\
\hline$z$ & height coordinate \\
\hline$z_{c}$ & $\begin{array}{l}\text { location of the diagonal compression strut } \\
\text { at the column edge }\end{array}$ \\
\hline$z_{I C R}$ & $\begin{array}{l}\text { height coordinate of the instantaneous } \\
\text { center of rotation }\end{array}$ \\
\hline$\alpha$ & $\begin{array}{l}\text { angle between failure surface and the } \\
\text { vertical axis }\end{array}$ \\
\hline$\beta$ & secant inclination of the failure surface \\
\hline$\dot{\gamma}_{n, t}$ & $\begin{array}{l}\text { deviatoric strain rate in a radial view of the } \\
\text { plastic zone along the failure surface }\end{array}$ \\
\hline$\Delta$ & thickness of the plastic zone \\
\hline$\dot{\varepsilon}_{n}, \dot{\varepsilon}_{t}$ & $\begin{array}{l}\text { normal and tangential strain rate in a radial } \\
\text { view of the plastic zone }\end{array}$ \\
\hline$\dot{\varepsilon}_{1}, \dot{\varepsilon}_{2}, \dot{\varepsilon}_{3}$ & principal strain rate \\
\hline$\dot{\varepsilon}_{c, t}$ & $\begin{array}{l}\text { concrete tangential strain rate in the outer } \\
\text { portion of the footing }\end{array}$ \\
\hline$\dot{\varepsilon}_{s, b}^{\tan }, \dot{\varepsilon}_{s, t}^{\tan }$ & $\begin{array}{l}\text { tangential strain rate in bottom and top } \\
\text { reinforcements }\end{array}$ \\
\hline$\eta_{\varepsilon}$ & $\begin{array}{l}\text { reduction factor accounting for the presence } \\
\text { of transverse strains }\end{array}$ \\
\hline$\eta_{f c}$ & $\begin{array}{l}\text { reduction factor accounting for the } \\
\text { brittleness of high-strength concrete }\end{array}$ \\
\hline$\eta$ & global reduction factor \\
\hline$\theta$ & principal strain directions \\
\hline$\rho$ & experimental bottom reinforcement ratio \\
\hline$\rho_{r}, \rho_{t}$ & $\begin{array}{l}\text { bottom reinforcement ratio in radial and } \\
\text { tangential directions }\end{array}$ \\
\hline$\rho_{r}^{\prime}, \rho_{t}^{\prime}$ & $\begin{array}{l}\text { top reinforcement ratio in radial and } \\
\text { tangential directions }\end{array}$ \\
\hline$\sigma_{1}, \sigma_{3}$ & principal stresses \\
\hline$\varphi$ & concrete friction angle \\
\hline$\chi$ & angle between velocity and failure surface \\
\hline$\dot{\psi}$ & $\begin{array}{l}\text { relative rotation rate around the } \\
\text { instantaneous center of rotation }\end{array}$ \\
\hline$\omega_{r}, \omega_{t}$ & $\begin{array}{l}\text { bottom mechanical reinforcement ratio in } \\
\text { radial and tangential direction }\end{array}$ \\
\hline$\omega_{r}^{\prime}, \omega_{t}^{\prime}$ & $\begin{array}{l}\text { top mechanical reinforcement ratio in radial } \\
\text { and tangential direction }\end{array}$ \\
\hline
\end{tabular}

\section{References}

[1] Talbot AN. Reinforced concrete wall footings and column footings. Bulletin 67, Engineering Experiment Station: University of Illinois; 1913. 114 pp.

[2] Richart FE. Reinforced concrete walls and column footings, Part 1 and 2. ACI J 1948;45. 97-127, 237-60.

[3] Moe J. Shearing strength of reinforced concrete slabs and footings under concentrated loads, vol. D47. Portland Cement Association; 1961. 135 pp..

[4] Kordina K, Nölting D. Load-carrying behavior of eccentrically loaded isolated reinforced concrete foundations. Technical report. DFG-Research Ko 204/2730, Brunswick, Germany; 1981. p. 158 [in German: Tragverhalten von ausmittig beanspruchten Einzelfundamenten aus Stahlbeton]. 
[5] Dieterle H, Rostásy F. Load-carrying behavior of isolated reinforced concrete foundations of square columns. Deutscher Ausschuss für Stahlbeton, vol. 387; 1987. p. 1-91 [in German: Tragverhalten quadratischer Einzelfundamente aus Stahlbeton].

[6] Dieterle H. Design of reinforced concrete foundations of square columns under centric loading with the help of design diagrams. Deutscher Ausschuss für Stahlbeton, vol. 387; 1987. p. 94-134 [in German: Zur Bemessung quadratischer Stützenfundamente aus Stahlbeton unter zentrischer Belastung mit Hilfe von Bemessungsdigrammen].

[7] Hallgren M, Kinnunen S, Nylander B. Punching shear tests on column footings. Nord Concr Res 1998;21:1-22.

[8] Hallgren M, Bjerke M. Non-linear finite element analyses of punching shear failure of column footings. Cement Concr Compos 2002;24(6):491-6.

[9] Timm M. Punching of foundation slabs under axisymmetric loading. Doctoral thesis. Institute for Building Materials, Concrete Structures and Fire Protection of the Technical University Braunschweig; 2003. p. 159 [in German: Durchstanzen von Bodenplatten unter rotationssymmetrischer Belastung].

[10] Broms CE. Concrete flat slabs and footings: design method for punching and detailing for ductility. Doctoral thesis. Stockholm (Sweden): Department of Civil and Architectural Engineering, Division of Structural Design and Bridges, Royal Institute of Stockholm; 2005. p. 114.

[11] Hegger J, Sherif A, Ricker M. Experimental investigations on punching behavior of reinforced concrete footings. ACI Struct J 2006;103(4):604-13.

[12] Ricker M. Punching in RC footings considering the soil-structure-interaction. In: Proceedings of the 6th int PhD symposium in civil engineering, Zürich, Switzerland; 2006.

[13] Hegger J, Ricker M, Ulke B, Ziegler M. Investigations on the punching behavior of reinforced concrete footings. Eng Struct 2007;29(9):2233-41.

[14] Hegger J, Ricker M, Sherif A. Punching strength of reinforced concrete footings. ACI Struct J 2009;106(5):706-16.

[15] Ricker M. Reliability of punching design of isolated foundations. Doctoral thesis. RWTH Aachen University; 2009. p. 304 [in German: Zur Zuverlässigkeit der Bemessung gegen Durchstanzen bei Einzelfundamenten].

[16] Urban T, Goldyn M, Krakowski J, Krawczyk L. Experimental investigation on punching behavior of thick reinforced concrete slabs. Arch Civ Eng 2013;59 (2):157-74.

[17] Siburg C, Hegger J. Experimental investigations on punching behaviour of reinforced concrete footings with structural dimensions. Struct Concr 2014;15 (3):331-9.

[18] Siburg C. Consistent punching design in flat slabs and foundations. Doctoral thesis. RWTH Aachen University; 2014. p. 333 [in German: Zur einheitlichen Bemessung gegen Durchstanzen in Flachdecken und Fundamenten].

[19] Drucker DC. On structural concrete and the theorems of limit analysis International Association for Bridge and Structural Engineering. IABSEReports, vol. 21, Zürich, Switzerland; 1961. p. 49-59.

[20] Leonhardt F, Walther R. Shear tests on single span beams with and without shear reinforcement. Deutscher Ausschuss für Stahlbeton, no. 151; 1962. 83 pp. [in German: Schubversuche an einfeldrigen Stahlbetonbalken mit und ohne Schubbewehrung].

[21] Muttoni A, Schwartz J. Behavior of beams and punching in slabs without shear reinforcement. In: IABSE proceedings, Stuttgart, Germany, vol. 62; 1991. p. 703-8.

[22] Muttoni A, Fernández Ruiz M. Shear strength of members without transverse reinforcement as function of critical shear crack width. ACI Struct J 2008;105 (2):163-72.

[23] Muttoni A. Punching shear strength of reinforced concrete slabs without transverse reinforcement. ACI Struct I 2008;105(4):440-50.

[24] Johansen KW. Yield-line theory. Cem Concr Assoc 1962:182.

[25] Gesund H, Dikshit OP. Yield line analysis of the punching problem at slab/column intersections. ACI Spec Publ 1971;30:177-201.
[26] Braestrup MW. Plastic analysis of shear in reinforced concrete. Mag Concr Res 1974;26(89):221-8.

[27] Jensen BC. Lines of discontinuity for displacements in the theory of plasticity of plain and reinforced concrete. Mag Concr Res 1975;2(2):143-50.

[28] Braestrup MW, Nielsen MP, Jensen BC, Bach F. Axisymmetric punching of plain and reinforced concrete. Report no. 75. Structural Research Laboratory, Technical University of Denmark; 1976. p. 33.

[29] Müller P. Plastic analysis of reinforced concrete disks and beams. Institut für Baustatik und Konstruction. Report no. 83, ETH Zurich; 1978. 160 pp. [in German: Plastische Berechnung von Stahlbetonscheiben und-balken].

[30] Nielsen MP, Braestrup MW, Bach F. Rational analysis of shear in reinforced concrete beams. In: IABSE proceedings, Bergamo, Italy, vol. 2, P-15/78; 1978. $16 \mathrm{pp}$.

[31] Nielsen MP, Braestrup MW, Jensen BC, Bach F. Concrete plasticity. Beam shear - shear in joints - punching shear. Special Publication, Danish Society for Structural Science and Engineering; 1978. p. 129.

[32] Braestrup MW. Punching shear in concrete slabs. In: IABSE colloquium plasticity in reinforced concrete, Copenhagen, Denmark; 1979. p. 115-36.

[33] Morley CT. Punching shear failure of hollow concrete spheres. In: IABSE colloquium plasticity in reinforced concrete, Copenhagen, Denmark; 1979. p. 167-74.

[34] Braestrup MW. Structural concrete as a plastic material. In: IABSE colloquium advanced mechanics of reinforced concrete, Delft, Holland; 1981. p. 3-16.

[35] Gesund H. Flexural limit analysis of concentrically loaded column footings. ACI J Proc 1983;80(3):223-8.

[36] Gesund H. Flexural limit design of column footings. J Struct Eng 1985;111 (11):2273-87.

[37] Jiang D-H, Shen J-H. Strength of concrete slabs in punching shear. J Struct Eng 1986;112(12):2578-91.

[38] Muttoni A. The applicability of the theory of plasticity to reinforced concrete design. Institut für Baustatik und Konstruction. Report no. 176, ETH Zurich; 1990. 159 pp. [In German: Die Anwendbarkeit der Plastizitätstheorie in der Bemessung von Stahlbeton].

[39] Bortolotti L. Punching shear strength in concrete slabs. ACI Struct J 1990;87 (2):208-19.

[40] Kuang JS. An upper-bound plastic solution for punching shear failure of concrete slabs. Report no. CUED/D-Struct/TR.136. United Kingdom: Engineering Department, University of Cambridge; 1991. p. 41.

[41] Muttoni A, Schwartz J, Thürlimann B. Design of concrete structures with stress fields. Basel (Switzerland): Birkhäuser Verlag: 1997.

[42] Salim W, Sebastian WM. Plasticity model for predicting punching shear strengths of reinforced concrete slabs. ACI Struct J 2002;99(6):827-35.

[43] Chen W-F. Plasticity in reinforced concrete. J. Ross Publishing; 2007.

[44] Fernández Ruiz M, Muttoni A. On development of suitable stress fields for structural concrete. ACI Struct J 2007;104(4):495-502.

[45] Nielsen MP, Hoang LC. Limit analysis and concrete plasticity. 3rd ed. Boca Raton (USA): CRC Press; 2011.

[46] Jensen UG, Hoang LC. Collapse mechanisms and strength prediction of reinforced concrete pile caps. Eng Struct 2012;35:203-14.

[47] Vecchio FJ. Disturbed stress field model for reinforced concrete: formulation. J Struct Eng 2000;126(9):1070-7.

[48] Vecchio FJ, Collins MP. The modified compression-field theory for reinforced concrete elements subjected to shear. ACI J 1986;83(2):219-31.

[49] Fernández Ruiz M, Muttoni A. Shear strength of thin-webbed post-tensioned beams. ACI Struct J 2008;105(3):308-17.

[50] Courant R, Hilbert D. Method of mathematical physics, vol. 1. New York (USA): John Wiley \& Sons, Interscience Publishers; 1953.

[51] Guidotti R, Fernández Ruiz M, Muttoni A. Crushing and flexural strength of slab-column joints. Eng Struct 2011;33(3):855-67.

[52] fib, Model Code 2010 - final draft, vols. 1 and 2. fib Bulletin 65, fib Bulletin 66; 2012. 350 pp. 